PALEO

Revue d'archéologie préhistorique

$20 \mid 2008$

Spécial table ronde ( $2^{\mathrm{e}}$ partie) : Le Gravettien : entités régionales d'une paléoculture européenne, Les Eyzies, juillet 2004

\title{
Le Gravettien des Pyrénées
}

The Gravettian of the Pyrenees

Pascal Foucher, Cristina San Juan-Foucher, Dominique Sacchi et Álvaro Arrizabalaga

\section{CpenEdition}

\section{Journals}

Édition électronique

URL : http://journals.openedition.org/paleo/1604

DOI : $10.4000 /$ paleo. 1604

ISSN : 2101-0420

Éditeur

SAMRA

Édition imprimée

Date de publication : 1 décembre 2008

Pagination : 331-356

ISSN : $1145-3370$

Référence électronique

Pascal Foucher, Cristina San Juan-Foucher, Dominique Sacchi et Álvaro Arrizabalaga, « Le Gravettien des Pyrénées », PALEO [En ligne], 20 | 2008, mis en ligne le 12 mai 2011, consulté le 07 juillet 2020.

URL : http://journals.openedition.org/paleo/1604 ; DOI : https://doi.org/10.4000/paleo.1604

\section{(ब) $\odot \Theta$}

PALEO est mis à disposition selon les termes de la licence Creative Commons Attribution - Pas d'Utilisation Commerciale - Pas de Modification 4.0 International. 


\title{
LE GRAVETTIEN DES PYRÉNÉES
}

\author{
Pascal FOUCHER ${ }^{(1)}$, Cristina SAN JUAN-FOUCHER ${ }^{(1)}$, \\ Dominique SACCHI ${ }^{(2)}$ et Álvaro ARRIZABALAGA ${ }^{(3)}$
}

\footnotetext{
Résumé : Les auteurs présentent un panorama général sur le Gravettien des Pyrénées. L'espace géographique retenu pour cette étude a été découpé en trois zones principales : le Pays Basque ibérique, les Pyrénées atlantiques et centrales, les Pyrénées orientales. La synthèse proposée se structure autour des quatre thèmes suivants :

- histoire des recherches et contexte chrono-stratigraphique ;

- culture matérielle : industrie lithique et osseuse ;

- témoignages artistiques et symboliques : parure, art mobilier et art pariétal ;

- le paléo-environnement.
}

Mots-clés : Le Gravettien, Les Pyrénées, industrie lithique et osseuse, parure, art mobilier et pariétal.

Abstract: The Gravettian of the Pyrenees. The authors present an overview about the Gravettian in the Pyrenees. The geographical area held for this study was divided into three main zones : the Iberian Basque country, the Atlantic and Central Pyrenees, the Eastern Pyrenees. The synthesis proposed is built around the four following topics :

- the history of researches and chronostratigraphic context;

- material culture: lithic and bone industries;

- artistic and symbolic evidences : body ornamentation, mobiliary art and rock art;

- palaeo-environment.

Key-words: The Gravettian, The Pyrenees, lithic and bone industries, body ornamentation, mobiliary art and rock art.

Avertissement. Le manuscrit de cet article a été déposé en octobre 2005. Il fait donc état de la recherche sur le Gravettien pyrénéen jusqu'à cette date et ne tient pas compte de l'ensemble des données récentes. Seules certaines références bibliographiques postérieures, faisant des synthèses sur des points précis, ont été ajoutées au moment de la correction des épreuves.

\section{INTRODUCTION}

Les découpages territoriaux ne sont pas évidents à l'heure de présenter des synthèses historiques (ou préhisto- riques). Nous avons fait ici le choix de considérer les Pyrénées comme une vaste entité géographique, sans oublier pour autant que les régions qui les composent sont très différentes tant du point de vue géomorphologique que climatique (Collectif 2005 ; Cazals et al. 2007). Cette diversité devait déjà exister aux temps préhistoriques, à la différence près des conditions climatiques générales. L'axe montagnard qui les réunit est leur dénominateur commun : cette barrière infranchissable en contexte pléniglaciaire, sauf à ses deux extrémités, a nécessairement joué un rôle important dans l'appropriation de l'espace par les préhistoriques (dont les Gravettiens) et leurs déplacements.

(1) Ministère de la Culture et de la Communication, Service régional de l'Archéologie de Midi-Pyrénées, 32 rue de la Dalbade, BP 811, 31080 TOULOUSE cedex 6 - UMR 5608 / Université de Toulouse-le-Mirail - pascal.foucher@culture.gouv.fr cristina.san-juan@culture.gouv.fr

(2) TRACES, UMR 5608 CNRS-CRPPM, 39 allées Jules Guesde, 31000 TOULOUSE - dominique.sacchi@wanadoo.fr (3) Universidad del País Vasco, Facultad de Filología y Geografía-Historia, c/ Tomás y Valiente s/n, 01006 VITORIA (Espagne) fgparvaa@vc.ehu.es 


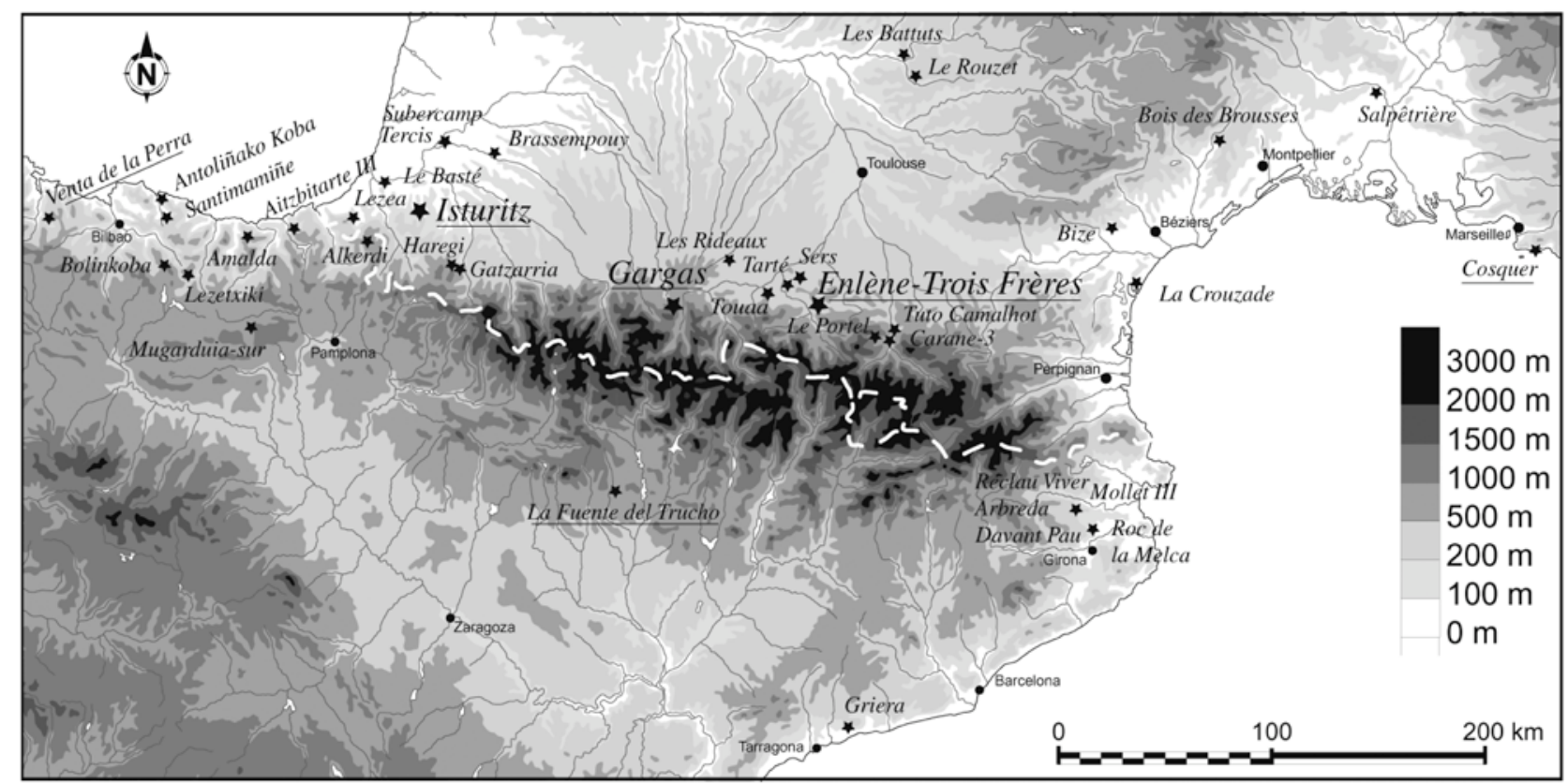

Figure 1 - Carte de localisation des sites gravettiens des Pyrénées (fond de carte : F. Tessier) - Les noms soulignés sur la carte correspondent soit à des sites gravettiens comprenant des parois ornées, soit à des sites pariétaux pouvant être rapportés au Gravettien.

Figure 1 - Map of the Gravettian sites in the Pyrenees. The names underlined on the map correspond to either Gravettian sites with decorated walls or rock art sites that could be correlated with Gravettian.

Nous proposons un balayage ouest-est (fig. 1), en commençant par l'ensemble des sites du Pays Basque ibérique, puis celui qui réunit ceux des Pyrénées atlantiques et centrales ; nous terminerons notre panorama par les Pyrénées méditerranéennes dans leur partie septentrionale, notre collègue J.M. Fullola se chargeant, dans ce volume, de traiter du Gravettien de la Catalogne. La partie méridionale des Pyrénées centrales, correspondant à la rive gauche de la moyenne vallée de l'Èbre, n'a révélé jusqu'à présent qu'un seul site d'art pariétal : La Fuente del Trucho (Huesca), dont les mains négatives se rapportent vraisemblablement au Gravettien, mais qui n'a pas livré de dépôt stratigraphique correspondant (Utrilla 2000, 2002 ; Foucher 2004 ; Ripoll et al. 2005). Le découpage retenu tente de répondre à la fois à une cohérence géo-archéologique et à l'histoire de la recherche franco-espagnole, tout en gardant une approche synthétique.

\section{Le Pays Basque péninsulaire (A. A.)}

Les premières mentions de gisements gravettiens dans le Pays Basque de la Péninsule ibérique sont antérieures aux travaux de Peyrony et, par conséquent, se rapportent à "l'Aurignacien supérieur", nomenclature préconisée alors par Breuil (Arrizabalaga 1998a) ; cette dernière est adoptée par T. de Aranzadi et J.M. de Barandiarán, autant à Santimamiñe (Aranzadi et Barandiarán J.M. 1935) qu'à Bolinkoba (Barandiarán J.M. 1950), ainsi que dans diverses synthèses (Barandiarán J.M. 1934 et 1953), ce qui engendrera par la suite une certaine confusion. À partir des travaux effectués et publiés dans les années 1950, cette terminologie est généralement remplacée par des références au "Gravettien", le terme de "Périgordien supérieur" ou les diverses phases du Périgordien proposées par Sonneville-Bordes n'étant quasiment pas usités (Arrizabalaga et Iriarte 1995). En revanche, l'expression "Aurignacopérigordien" qu'elle soit orthographiée en séparant les deux termes (Barandiarán I. 1980) ou en un seul mot (Ruiz ldarraga 1990), est beaucoup plus présente dans les publications comme synonyme du Paléolithique supérieur initial. Par ailleurs, il faut mentionner la proposition de McCollough (1971) de l'existence du "Noaillien" dans la partie médiane de la Corniche cantabrique, culture à laquelle sont rattachés les gisements riches en burins de Noailles se distribuant d'Isturitz à Bolinkoba.

Après les travaux déjà mentionnés à Santimamiñe et à Bolinkoba, ainsi que la brève opération effectuée à Usategi (Barandiarán J.M. 1977), il faut attendre les années 1980 pour que de nouvelles fouilles soient réalisées sur des gisements gravettiens. La fouille d'Amalda en premier lieu, suivie par les différents travaux de terrain menés à Aitzbitarte-III, Mugarduia-Sur, Legintxiki, Antoliñako Koba, Alkerdi et Irikaitz, ont permis d'étoffer significativement le registre de sites se rapportant au Gravettien. Ces derniers sites ont apporté chacun leur lot d'informations, comme une date ${ }^{14} \mathrm{C}$ à Alkerdi, la caractérisation de l'industrie lithique de Mugarduia-Sur, ainsi que celle de la faune récupérée à Legintxiki. Mais, à l'exception d'Amalda (Altuna, Baldeón et Mariezkurrena 1990), il manque encore des publications monographiques détaillées pour chacun de ces sites. Enfin, il faut souligner que la révi- 


\begin{tabular}{|c|c|c|c|c|c|c|}
\hline Gisement & Référence & Méthode & Échantillon & Date & Niveau & Référence biblio. \\
\hline Aitzbitarte III & Ua & AMS & $0 \mathrm{~s}$ & $28950 \pm 655$ & IV & Altuna 2003 \\
\hline Zatoya & GrN-23999 & $\mathrm{C} 14$ & $0 \mathrm{~s}$ & $28870+760-690$ & Ilbam. Premier Tiers Pal. Sup. & Barandiarán \& Cava 2001 \\
\hline Aitzbitarte III & $\mathrm{Ua}$ & AMS & os & $28320 \pm 605$ & IV & Altuna 2003 \\
\hline Aitzbitarte III & $\mathrm{Ua}$ & AMS & $0 \mathrm{~s}$ & $27580 \pm 550$ & IV & Altuna 2003 \\
\hline Amalda & I-11664 & $\mathrm{C} 14$ & $0 \mathrm{~s}$ & $27400 \pm 1100$ & VI. Gravettien & Altuna et $a l .1990$ \\
\hline Amalda & $\mathrm{I}-11665$ & $\mathrm{C} 14$ & $0 \mathrm{~s}$ & $27400 \pm 1000$ & VI. Gravettien & Altuna et $a l .1990$ \\
\hline Antoliñako Koba & GrN-23786 & $\mathrm{C} 14$ & ¿? & $27390 \pm 320$ & Lmbk sup. Gravettien & Aguirre 2000 \\
\hline Alkerdi & & & & $26470 \pm 470$ & Gravettien & Barandiarán 1996 \\
\hline Aitzbitarte III & Ua-2244 & AMS & $0 \mathrm{~s}$ & $25380 \pm 430$ & VI. Gravettien & Altuna 1992 \\
\hline Aitzbitarte III & Ua-2245 & AMS & $0 \mathrm{~s}$ & $24920 \pm 410$ & VI. Gravettien & Altuna 1992 \\
\hline Aitzbitarte III & $\mathrm{I}-15208$ & $\mathrm{C} 14$ & $0 \mathrm{~s}$ & $24910 \pm 770$ & V. Gravettien & Altuna 1992 \\
\hline Aitzbitarte III & Ua-2627 & AMS & $0 \mathrm{~s}$ & $24635 \pm 475$ & VI. Gravettien & Altuna 1992 \\
\hline Aitzbitarte III & Ua-2626 & AMS & $0 \mathrm{~s}$ & $24545 \pm 415$ & VI. Gravettien & Altuna 1992 \\
\hline Aitzbitarte III & Ua-2628 & AMS & 0s & $23830 \pm 345$ & VI. Gravettien & Altuna 1992 \\
\hline Aitzbitarte III & Ua-2243 & AMS & $0 \mathrm{~s}$ & $23230 \pm 330$ & V. Gravettien & Altuna 1992 \\
\hline Aitzbitarte III & Ua-1917 & AMS & $0 \mathrm{~s}$ & $21130 \pm 130$ & VI. Gravettien & Altuna 1992 \\
\hline Ekain & I- 13005 & $\mathrm{C} 14$ & $0 \mathrm{~s}$ & $20900 \pm 450$ & VIII. Würm III/IV & Altuna 1984 \\
\hline Tarté & OxA-12082 & AMS & Renne & $28410 \pm 150$ & clc. Gravettien & Foucher 2004 \\
\hline Enlène-EDG & GifA-97306 & AMS & Cerf & $27980 \pm 480$ & c5. Gravettien & Foucher et $a l .2002$ \\
\hline Grargas & GifA-92369 & AMS & Os & $26860 \pm 460$ & Os fiché dans paroi des mains peintes & Clottes et al. 1992 \\
\hline Tarté & OxA-12081 & AMS & Bovidé & $26600 \pm 170$ & clb. Gravettien & Foucher 2004 \\
\hline La Carane-3 & GifA-100404 & AMS & Os & $26490 \pm 390$ & c.1.3. Gravettien & Foucher et $a l .2002$ \\
\hline Enlène-EDG & GrA-19734 & AMS & Renne & $25850 \pm 360$ & c5. Gravettien & Foucher 2004 \\
\hline Gargas & GrA-19506 & AMS & Renne & $25050 \pm 170$ & Gravettien & Foucher 2004 \\
\hline Enlène-EDG & Gif-6656 & $\mathrm{C} 14$ & Os & $24600 \pm 350$ & c5. Gravettien & Clottes 1989 \\
\hline Tuto de Camalhot & GrA-14938 & AMS & Bouquetin & $24220 \pm 160$ & Gravettien & Foucher et al. 2002 \\
\hline La Carane-3 & GifA-99245 & AMS & Cert & $23710 \pm 270$ & c.1.2. Gravettien & Foucher et al. 2000 \\
\hline Tuto de Camalhot & GrA-14939 & AMS & Cheval & $23380 \pm 150$ & Gravettien & Foucher et al. 2002 \\
\hline Tuto de Camalhot & Gif-2942 & $\mathrm{C} 14$ & Os & $21500 \pm 400$ & Gravettien & Bui-Thi-Mai, Girard 1984 \\
\hline Grotte du Pape GG2 & Gif- 8175 & $\mathrm{C} 14$ & Os & $19700 \pm 160$ & 2d. "Épigravettien" & Buisson 1996 \\
\hline
\end{tabular}

Figure 2 - Récapitulatif des dates ${ }^{14} \mathrm{C}$ disponibles pour le Gravettien des Pyrénées.

Figure $2-{ }^{14} \mathrm{C}$ dates of the Gravettian in the Pyrenees.

sion de tous les niveaux réputés comme étant gravettiens a abouti à une remise en question de l'attribution gravettienne de certains d'entre eux (niveau II de Lezetxiki et niveau $\mathrm{V}$ de Amalda). Le niveau II de Lezetxiki peut probablement être attribué à un Solutréen qui contient des burins de Noailles (Arrizabalaga et al. 2005). Quant au niveau V d'Amalda, une attribution au Protomagdalénien ou au Périgordien VII avait d'abord été avancée, mais il pourrait correspondre en réalité à un Solutréen avec très peu de pièces "caractéristiques" (Arrizabalaga 1995). La permanence de burins de Noailles en contexte solutréen, observée de manière récurrente dans divers gisements basques, vient d'être encore constatée lors de récentes fouilles à Antoliñako Koba (Aguirre 2000) et à Aitzbitarte-III (Altuna 2002).

Si l'on établit une liste récapitulative des gisements ayant livré de manière certaine des niveaux gravettiens, dans la région basque au sud des Pyrénées, on peut comptabiliser huit sites : en Bizkaia, Santimamiñe (Aranzadi et Barandiarán J.M. 1935), Bolinkoba (Barandiarán J.M. 1954 et 1974) et Antoliñako Koba (Aguirre 2000) ; en Gipuzkoa, Amalda (Altuna, Baldeón et
Mariezkurrena 1990), Usategi (Barandiarán J.M. 1977), Irikaitz (Arrizabalaga et Iriarte 2003) et Aitzbitarte-III (Altuna 1992b et 2002) ; en Alava, aucun site ; en Navarra, on ne retiendra qu’Alkerdi (Barandiarán I. 1996 et 1997). Avec quelques hésitations, nous pourrions ajouter à cette liste le niveau II de Lezetxiki (Arrizabalaga 1995), quelques séries de Jaizkibel (Gipuzkoa), une série issue d'un site plein air de la région de Alava (Pelbarte, Sáenz de Buruaga 1996), les deux niveaux de Legintxiki (Nuin 1994) et de Mugarduia-Sur en Navarra (Barandiarán I. 1988a). À l'exception de Irikaitz, Mugarduia-Sur et Jaizkibel, tous ces gisements se situent en grottes ou abris, même si la portée de cette remarque doit être tempérée par la difficulté à découvrir des dépôts de plein air, en raison de l'épais couvert végétal de la région.

Le cadre chronologique est bien documenté, notamment à partir de la série étoffée de dates ${ }^{14} \mathrm{C}$ de Aitzbitarte-III, complétée par celles d'Amalda, Alkerdi et Antoliñako Koba (fig. 2). D'un point de vue général, la première moitié du Gravettien, approximativement entre 27000 et 24000 BP, est bien représentée. En revanche, rares sont les dates se rapportant à la 

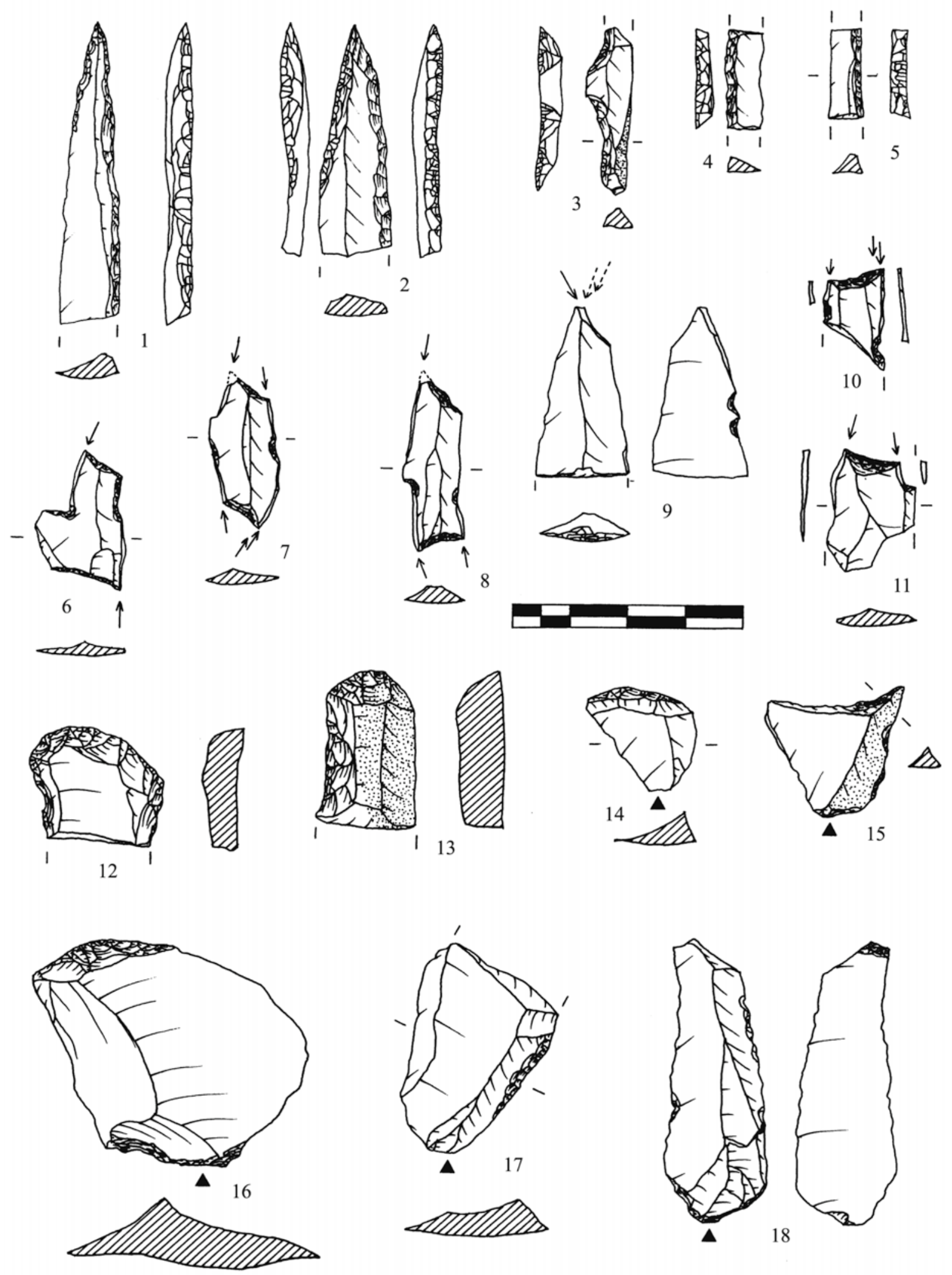

Figure 3 - Industrie lithique de Bolinkoba.

Figure 3 - Lithic industry from Bolinkoba. 
seconde moitié, entre 24000 et 20500 BP ; ce fait pourrait trouver son origine dans l'hypertrophie du Gravettien, entrainée par le «vieillissement» des dates de la première partie du Paléolithique supérieur. On remarquera le recouvrement chronologique d'un millénaire, entre 28000 et 27000 , avec l'Aurignacien évolué (cf. Barandiarán I., Fortea et Hoyos 1996), ainsi que la relative confusion entre la fin du Gravettien et le début du Solutréen (bien visible dans le niveau $\mathrm{V}$ de Amalda). Dans ce contexte, les diverses phases du Périgordien proposées par Sonneville-Bordes, notamment celles postérieures au Périgordien Vc à burins de Noailles, compliquent le cadre chronostratigraphique.

Du point de vue de la culture matérielle, les burins de Noailles caractérisent les séries lithiques (à l'exception de Mugarduia-Sur), qu'ils apparaissent en petit ou en grand nombre (on décompte plusieurs milliers de ces pièces à Aitzbitarte-III). Si on considère toujours le cas de MugarduiaSur comme une exception, il n'existerait pas ici d'autre faciès gravettien comme, par exemple, celui à nombreux éléments à dos abattu et sans burins de Noailles, présent à Cueva Morín, dans la région voisine de Cantabria. Nous ne savons pas si ce contexte archéologique peut correspondre à une phase plus évoluée (ou antérieure) du Gravettien, mais il est certain qu'il n'existe pas de niveau géochronologique s'y référant. Dans tous les cas, les éléments à dos abattu (en particulier les pointes à dos dont certaines sont d'authentiques pointes de La Gravette) constituent le second trait typologique significatif de ces ensembles lithiques gravettiens (fig. 3). Quant à l'industrie osseuse, les sagaies d'Isturitz sont présentes (Usategi, Bolinkoba, Aitzbitarte-III), même dans des séries très pauvres comme à Usategi. Elles représentent, de loin, l'élément le plus caractéristique, le reste de l'industrie osseuse étant peu diversifiée dans les Pyrénées méridionales et cela jusqu'au Solutréen moyen.

Nous ne disposons pas, pour le moment, de datations directes d'ensembles pariétaux conformes à la chronologie gravettienne. Cependant, les gravures profondes de la grotte de Venta Laperra et les peintures tamponnées de celle d'Arenaza, toutes deux situées en Bizkaia, ont été rapportées au Gravetto-Solutréen selon des critères stylistiques (Barandiarán I. 1988b). II n'existe pas non plus d'exemples remarquables d'art mobilier, si ce n'est les biseaux incisés des sagaies d'Isturitz, certains éléments de parure (croches de Cervidés, coquilles de Littorina et de Nassa) ainsi que des os, généralement d'oiseaux, gravés d'incisions (en série ou non).
Les stratégies d'exploitation des ressources naturelles dans le Gravettien basque péninsulaire commencent à être bien connues (Altuna 1990 ; Castaños 1986 ; Yravedra s.p.). On observe un degré de spécialisation relativement poussé dans la gestion des ressources animales bien que celle-ci ne se centre pas toujours sur la même espèce. La chasse intensive au Bouquetin et au Chamois (Isard) est pratiquée dans des environnements rocheux, comme à Bolinkoba ou à Amalda, alors qu'à Aitzbitarte-III les données récentes de la fouille semblent indiquer une préférence pour les grands Bovinés, et à Santimamiñe, c'est plutôt le Cerf. L'exploitation des ressources piscicoles a été mise en évidence à Amalda (salmonidés). Les études sur les stratégies d'acquisition en matières lithiques, où domine le silex (Arrizabalaga 1998b), révèlent des pratiques beaucoup plus standardisées. Au Gravettien, les trois principaux gîtes basques (Urbasa, Treviño et Flysh littoral) sont déjà connus et exploités systématiquement, bien que les ressources proches des sites archéologiques restent dominantes (Tarriño 2001 et 2003). Les données préliminaires sur le site de Irikaitz indiquent une présence marginale de silex nord-pyrénéens, notamment en provenance de Chalosse, et l'existence de quelques éclats de silex de type bergeracois est accréditée à Antoliñako Koba.

En conclusion, dans l'attente de la publication de nouvelles données relatives aux fouilles en cours, notre information sur le paléoenvironnement reste encore très limitée. L'interprétation écologique induite par l'archéozoologie présente une vision ambivalente (Altuna 1992a) et nous ne disposons pas d'autres études sédimentologiques et palynologiques que celles d'Amalda (Areso et al. 1990 ; Dupré 1990). Cependant, sur ce dernier site, les données s'accordent parfaitement pour souligner un épisode froid dans la séquence du niveau VI et une notable amélioration dans le niveau susjacent $\mathrm{V}$ (avec les réserves que nous avons déjà émises à propos de la filiation de ce dernier niveau). En général, les données paléoenvironnementales relatives au Gravettien basque péninsulaire indiquent une prédominance du froid.

\section{Les Pyrénées atlantiques et centrales (P. F. et C. S. J.)}

Histoire des recherches et contexte chronostratigraphique

L'historiographie du Gravettien pyrénéen connaît ses premiers faits marquants à la fin du XIX ${ }^{e}$ siècle et durant la première moitié du $X X^{e}$ siècle, lors des découvertes et des

(4) On ne donnera ici que quelques repères chronologiques très généraux concernant ces trois célèbres sites. Pour plus de détails, cf. Foucher 2004 et Normand 2007 pour Isturitz en particulier.

La grotte du Pape à Brassempouy, découverte en 1880, fut d'abord fouillée par Dubalen (1881-1882), puis livrée à des pillages anarchiques ou organisés (notamment lors du Congrès de l'Association Française pour l'Avancement des Sciences de 1892), jusqu'en 1894, date à laquelle Piette et de Laporterie commencèrent leurs fouilles plus systématiques. La grotte de Gargas est fréquentée au moins depuis le XVe siècle comme l'attestent certains graffiti. Les premières fouilles ont été effectuées par F. Garrigou et $A$. de Chasteigner en 1870. Puis, F. Régnault fouille dans divers endroits de la grotte de 1873 à 1900 et trouve les premières mains peintes en 1906. La découverte de l'art pariétal attirera l'attention de $E$. Cartailhac et $H$. Breuil qui réaliseront des fouilles en 1911 et 1913, mais leurs résultats ne seront que partiellement publiés 45 ans plus tard. La grotte d'Isturitz est fouillée d'abord par E. Passemard de 1912 à 1922, avec quelques interruptions, notamment lors de la Grande Guerre ou en 1917 à l'occasion de ses recherches à l'abri Olha à Cambo; R. et S. de Saint-Périer lui succèdent de 1928 à 1950 (R. de Saint-Périer meurt en 1950). 
fouilles des sites désormais célèbres de Brassempouy (Landes), Gargas (Hautes-Pyrénées) et Isturitz (Pyrénées atlantiques) ${ }^{4}$. A ces sites majeurs, il faut ajouter la grotte de Tarté (Haute-Garonne), malheureusement trop tôt fouillée, voire même pillée, dont on retiendra les deux niveaux gravettiens partiellement fouillés par E. Cartailhac et publiés par J. Bouyssonie (1939), les seuls ayant fait l'objet d'un traitement scientifique.

Pour la grotte du Pape à Brassempouy, on doit à H. Delporte (1968) d'avoir dénoué une partie de l'écheveau des données de E. Piette ; on peut ainsi retenir que le remplissage originel de l'Avenue et de la Grande Galerie devait receler deux niveaux gravettiens : la "couche des statuettes» et celle «audessus des statuettes et à grandes lames».

À Gargas, l'ensemble gravettien (niveaux 6 et 5 : «Aurignacien supérieur») a été caractérisé par $\mathrm{E}$. Cartailhac et $\mathrm{H}$. Breuil lors de leur fouille dans la salle principale (Salle l) en 1911 et 1913. Leurs travaux fourniront la première séquence stratigraphique de référence pour le site, ainsi que les éléments pour la datation relative de son art pariétal, mais l'importance de cet habitat, situé à proximité des mains peintes, ne semble pas avoir particulièrement retenu l'attention des chercheurs par la suite, en raison peutêtre de sa publication très tardive (Breuil, Cheynier 1958).

La grotte d'Isturitz a livré deux ensembles gravettiens dans la Salle Nord, bien caractérisés tant par E. Passemard (FIII et C ; 1944) que par R. de Saint-Périer (Ist. IV et Ist. III ; 1952). Le niveau supérieur Ist. III avait été attribué au Gravettien final par R. de Saint-Périer («Aurignacien final») mais le matériel lithique, dans sa composition typologique, n'indique pas vraiment une évolution chronologique (Foucher 2004), à l'exception peut-être des pointes de La Gravette qui présentent quelques changements formels (Simonet 2005). En revanche, quelques éléments intrusifs de la couche supérieure (solutréenne) ont pu être repérés.

À partir des années 1950, les études sur le Gravettien pâtissent du très faible nombre de fouilles se rapportant aux gisements de cette période. On ne compte plus que la fouille de G. Laplace sur le site de Gatzarria, de 1961 à 1976, où un niveau à burins de Noailles est mis en évidence (Sáenz de Buruaga 1995). La seule publication parue au cours de cette période est celle de J. et J. Vézian relative au site de La Tuto de Camalhot, fouillé de 1927 à 1934 (Vézian 1966).

Un nouveau regain d'intérêt pour le Gravettien pyrénéen se perçoit à la fin du $X X^{e}$ siècle. De nouvelles fouilles sont entreprises dans les différentes grottes de Brassempouy, d'abord sous la direction de $\mathrm{H}$. Delporte et $\mathrm{D}$. Buisson, à partir de 1981 (Delporte 1996 ; Buisson 1996), poursuivies ensuite par D. Gambier et F. Bon $(2000,2002)$. Ces derniers travaux ont mis en évidence un niveau gravettien à burins de Noailles, pointes de la Gravette et pointes à cran (Dartiguepeyrou 1995 ; Buisson 1996 ; Klaric 2003). Un nouveau gisement est aussi découvert dans un diverticule de la grotte d'Enlène (Enlène-EDG, Ariège), fouillé par J. Clottes et R. Bégouën de 1983 à 1990 (Clottes 1989 ; Foucher 2004). La collection d'Isturitz a fait l'objet de nouvelles synthèses universitaires (Mújika Alustiza 1991 ; Esparza San Juan 1995 ; Esparza San Juan, Mújika Alustiza 1996 ; Goutas 2004 ; Simonet 2005). Enfin, un programme de recherche, commencé en 1997, a permis une révision du registre documentaire gravettien (Foucher, San Juan 1998 ; 2004), l'élaboration d'une synthèse sur les industries lithiques des deux versants des Pyrénées (Foucher 2004), ainsi que la réalisation de sondages d'évaluation à La Carane-3 (Foucher, San Juan, Martin 2000) et à Gargas (Foucher, San Juan 2004 ; Foucher 2006 ; Foucher et al. 2008).

Même si la quinzaine de dates ${ }^{14} \mathbf{C}$ disponibles est encore insuffisante (fig. 2) pour établir une séquence chrono-stratigraphique rigoureuse, quelques tendances commencent à apparaître. Un regroupement de dates entre 28500 et $26000 \mathrm{BP}$ marquerait une phase ancienne. La phase moyenne (et récente) se situerait entre 25000 et 23000 $\mathrm{BP}$, mais nous disposons de très peu de données fiables sur une éventuelle phase récente et sur la transition Gravettien / Solutréen dans la région.

\section{Culture matérielle : industries lithiques et osseuses}

Tout comme dans le Pays Basque péninsulaire, on peut constater une grande homogénéité dans les industries lithiques gravettiennes des Pyrénées atlantiques et centrales ; elles se caractérisent typologiquement par :

- les éléments à dos (pointes de La Gravette, des Vachons et microgravettes) ;

- les burins de Noailles ;

- les pièces esquillées ;

- l'absence des pointes de La Font-Robert, qui apparaissent paradoxalement bien plus à l'ouest, sur les sites de Irikaitz (Pais Vasco) Cueva Morín (Cantabria) et de La Viña (Asturias), ou dans l'arrière pays pyrénéen, vers le nord, à l'abri Les Battuts (Tarn).

Ces groupes typologiques sont prépondérants dans les assemblages lithiques de tous les gisements (fig. 4 et 5) ; des variations statistiques peu significatives existent entre les sites, mais elles ne semblent pas indiquer une évolution diachronique; des facteurs autres que culturels (biais des calculs statistiques dans de nombreux cas, occasionnés par des tris sélectifs opérés par certains anciens fouilleurs) ainsi que l'existence de variabilités fonctionnelles (sites "spécialisés») peuvent aussi bien les provoquer. En tout état de cause, les séries lithiques provenant de sites anciennement fouillés (Isturitz, Gargas, Tarté) et d'autres, fouillés récemment (Enlène), présentent de grandes similitudes, tant dans la structuration générale de leur outillage que dans les formes et techniques de façonnage de certaines pièces (pointes de La Gravette, burins de Noailles, pièces esquillées). Ceci est davantage marquant si l'on considère les variables forcément induites par l'hétérogénéité des occupations et les éventuelles différences fonctionnelles de ces gisements. D'un point de vue technologique, il n'est pas encore possible d'apporter des précisions d'ordre chrono-culturel ou d'envisager l'existence de « sous-faciès » (Simonet $2005:$ 75).

II faut souligner qu'on ne retrouve pas dans les Pyrénées centrales et occidentales les autres cortèges 

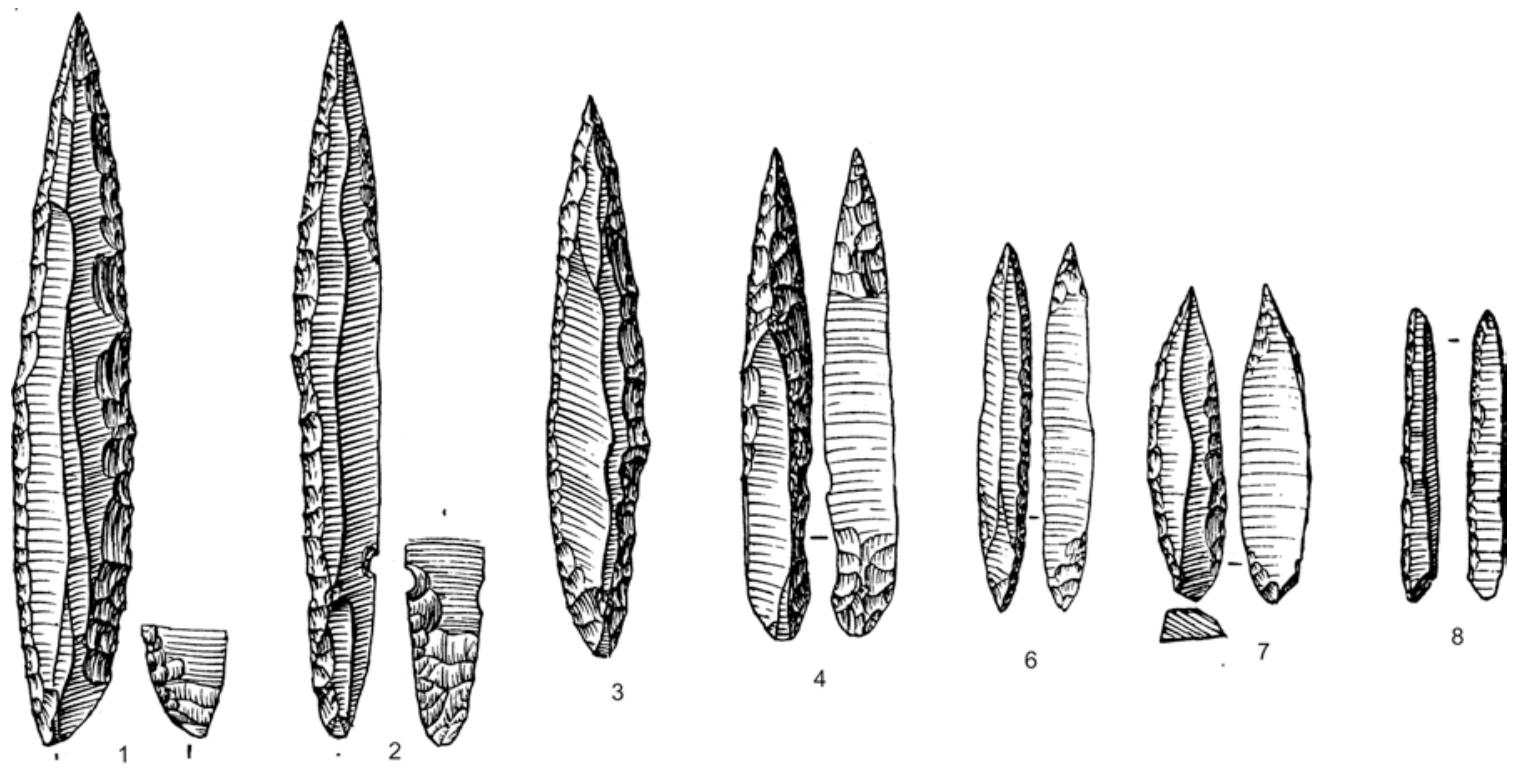

0
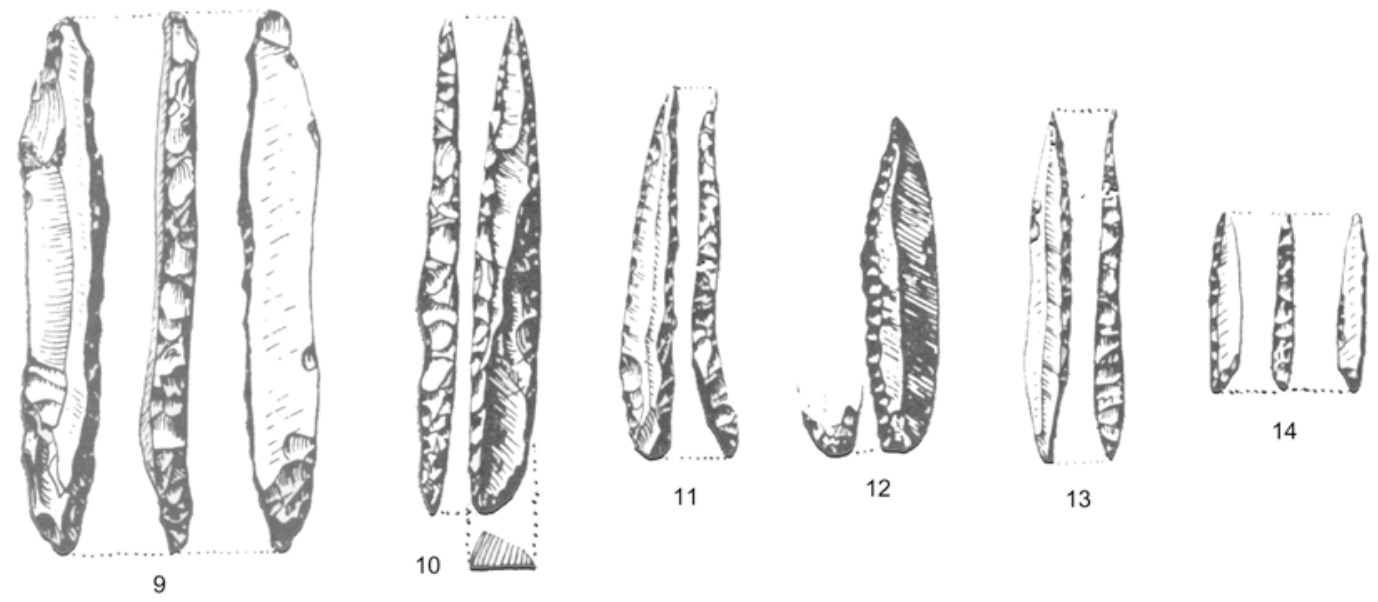

14
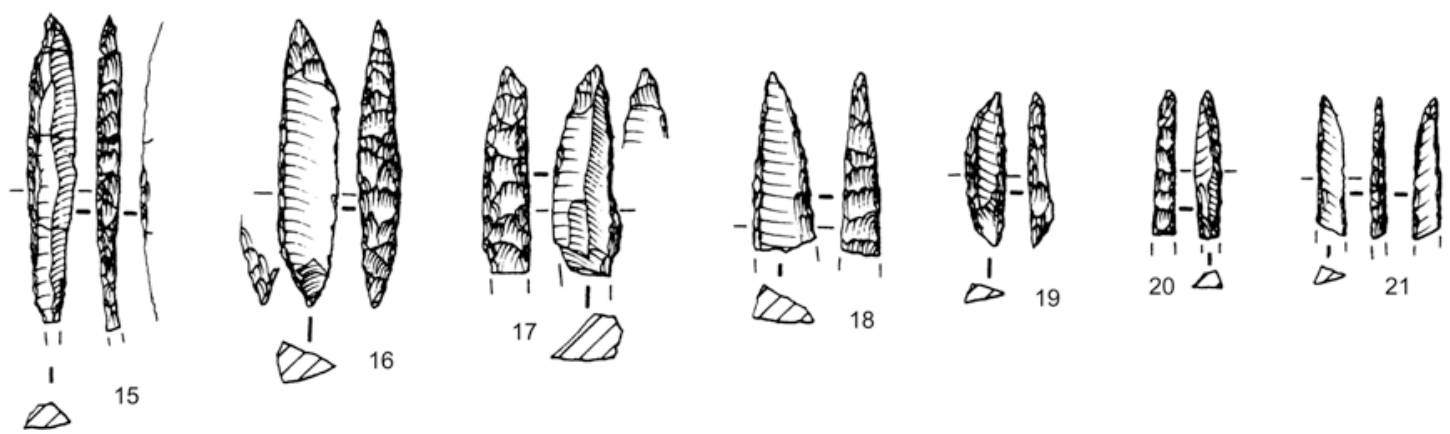

Figure 4 - Pointes de La Gravette. 1 à 8 : niveau IV d'Isturitz (Saint-Périer 1952). 9 à 14 : Gargas (Breuil, Cheynier 1958). 15 à 21 : c5 de Enlène-EDG (Clottes 1989).

Figure 4 - Gravette's points. 1 à 8 : niveau IV d'Isturitz (Saint-Périer 1952). 9 à 14 : Gargas (Breuil, Cheynier 1958). 15 à 21 : c5 de Enlène-EDG (Clottes 1989). 


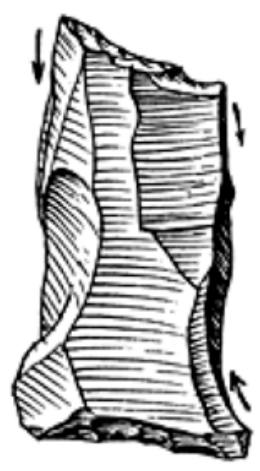

1
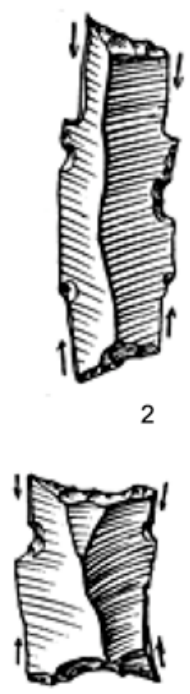

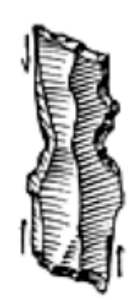

3

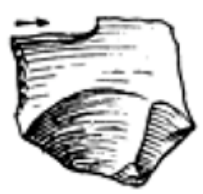

8

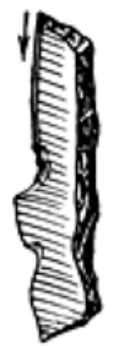

4

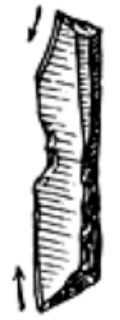

5

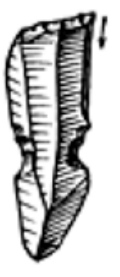

6
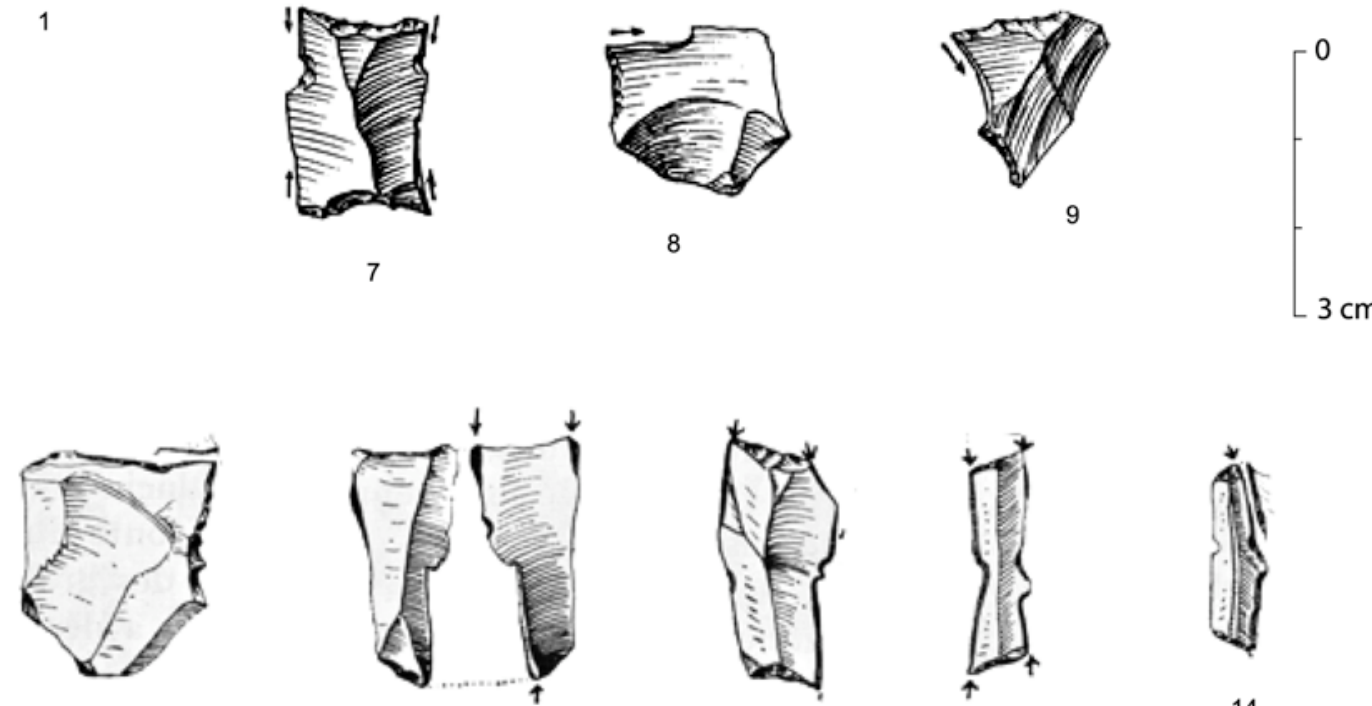

11

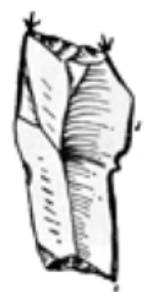

12

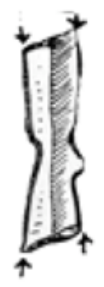

13

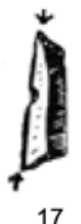

17

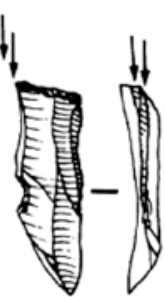

20

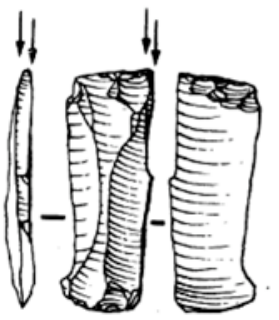

21

Figure 5 - Burins de Noailles. 1 à 9 : niveau IV d'Isturitz (Saint-Périer 1952). 10 à 17 : Gargas (Breuil, Cheynier 1958). 18 à 21 : c5 de Enlène-EDG (Clottes 1989).

Figure 5 - Noailles burins. 1 à 9 : niveau IV d'Isturitz (Saint-Périer 1952). 10 à 17 : Gargas (Breuil, Cheynier 1958). 18 à 21 : c5 de Enlène-EDG (Clottes 1989). 

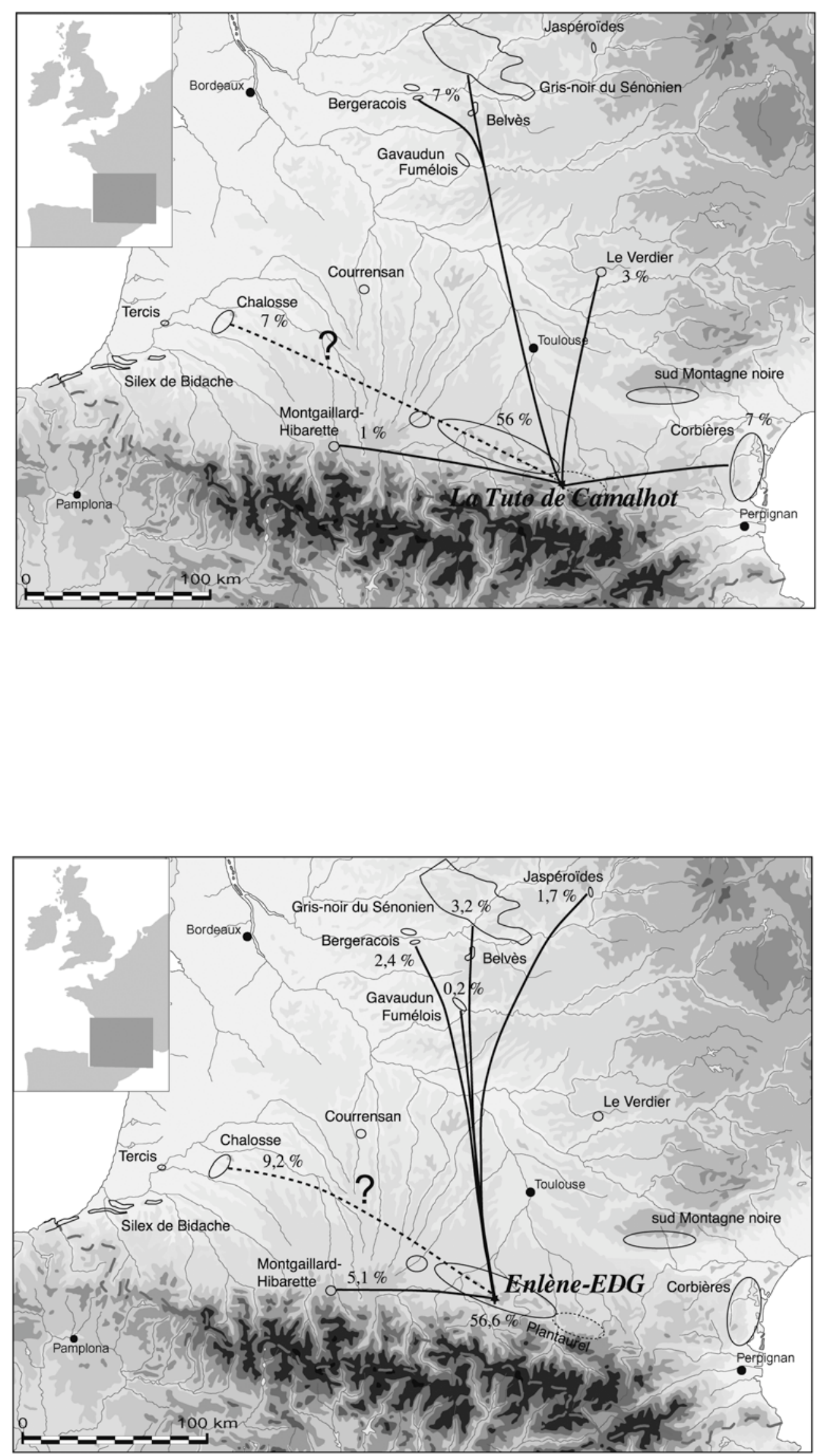

Figure 6-Cartographie des provenances des silex (outils) du niveau gravettien de la Tuto de Camalhot (fond de carte F. Tessier).

Figure 6-Map of raw material procurement (tools) from the

Gravettian layer in Tuto de Camalhot.
Figure 7 - Cartographie des provenances des silex (outils) de la couche c5 d'Enlène-EDG (fond de carte F. Tessier).

Figure 7 - Map of raw material procurement (tools) from the EnlèneEGD layer c5. 


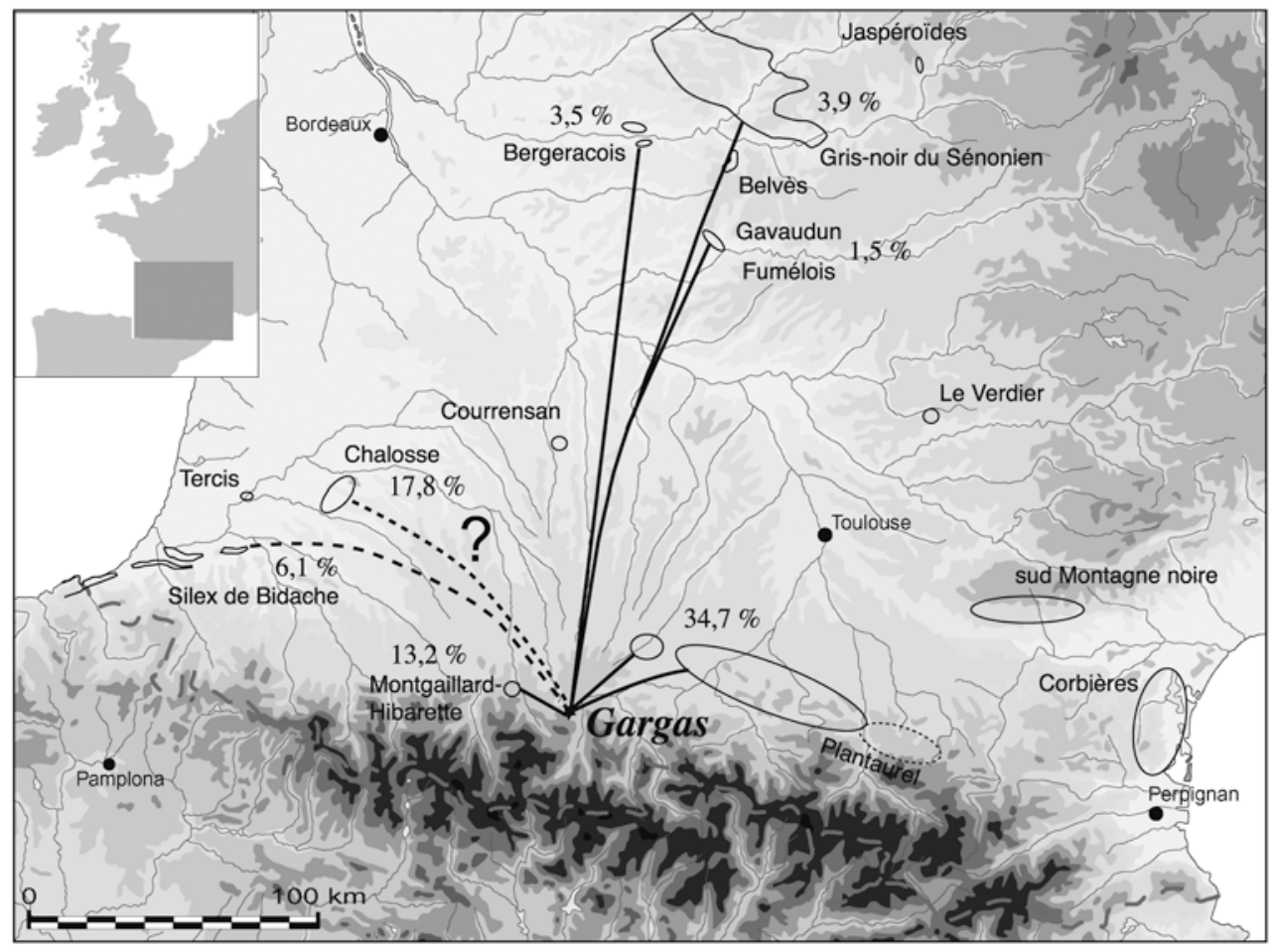

Figure 8 - Cartographie des provenances des silex (outils) du niveau gravettien de Gargas (fond de carte F. Tessier).

Figure 8 - Map of raw material procurement (tools) from the Gargas Gravettian layer.

industriels et procédés techniques définis dans le Périgord comme les fléchettes, les pointes de La FontRobert, les procédés liés aux burins de Raysse, etc., considérés comme des marqueurs de courants chronoculturels au sein du Gravettien. Le terme de "Noaillien» pourrait s'appliquer parfaitement aux ensembles pyrénéens. Bien que les dates ${ }^{14} \mathrm{C}$ suggèrent d'une part, l'émergence précoce de ce faciès (autour de $28000 \mathrm{BP}$ ) et d'autre part, sa longue permanence dans ce secteur tout au long de la durée de la culture gravettienne, l'existence d'un Gravettien ancien comprenant seulement des pointes de La Gravette et/ou des microgravettes n'est pas non plus à écarter.

L'économie des matières siliceuses ${ }^{5}$ se fonde sur une exploitation légèrement prédominante des ressources locales (silex des Petites Pyrénées), de l'ordre de 55-60 \% des supports d'outils. Néanmoins, la part des silex allochtones est encore importante, puisqu'elle représente 25$30 \%$ de l'outillage (le reste est d'origine indéterminée). Les principaux gîtes de provenance du silex sont : la Chalosse/Audignon ${ }^{6}$ et le Flysch (dont Hibarette) pour la partie ouest de la chaîne pyrénéenne ; les Corbières maritimes à l'Est et le Périgord (Bergeracois, Gris-Noir du
Sénonien, Jaspéroïdes de l'Infralias) au Nord. Ces horizons géographiques évoquent des distances de transport de plus de $250 \mathrm{~km}$ pour les plus éloignés. Leur pourcentage varie selon la localisation géographique des sites d'habitat (fig. 6 , 7). L'exemple le plus démonstratif concerne les silex orientaux (Corbières maritimes) ; ceux-ci n'apparaissent que dans les sites les plus à l'Est de la chaîne pyrénéenne (La Carane-3, La Tuto de Camalhot). Les matières ont été apportées sous forme de supports déjà débités, voire retouchés, ou de nucléus mis en forme ou en cours de débitage.

Sur le site de Gargas, où toutes les matières premières peuvent être considérées comme allochtones (fig. 8), on constate un équilibre entre la part des silex des Petites Pyrénées (35\%) et les silex de l'Ouest (Flysch/Hibarette : $19 \%$, Chalosse/Audignon ${ }^{6}: 18 \%$ ). Les silex du Nord viennent en complément, à hauteur de $10 \%$ (Gris-noir du Sénonien, Bergeracois, Fumélois-Gavaudun).

Les objets fabriqués en matières dures d'origine animale trouvés dans les gisements gravettiens pyrénéens appartiennent à quatre catégories typo-fonctionnelles : les armatures de chasse, l'outillage domestique, la parure et l'art mobilier.

(5) Nous avons pu compter sur la collaboration de R. Simonnet, M.-R. et M. Séronie-Vivien, A. Morala, Ch. Normand, A. Tarriño et $F$. Briois. Nous les en remercions ici très chaleureusement.

(6) La récente caractérisation d'une nouvelle source de matière première siliceuse dans les Pyrénées centrales (silex à Lépidorbitoïdes), très proche de celle qu'on rencontre en Chalosse/Audignon, devrait modifier, dans les années à venir, notre approche des circuits d'approvisionnement et de déplacements des matières premières au Paléolithique supérieur (Séronie-Vivien, Foucher 2006). L'ensemble des collections gravettiennes sont en cours de révision et analysées désormais à l'aune de cette nouvelle découverte. 
Les matières premières utilisées sont principalement les bois de cervidés (surtout le Cerf et le Renne, mais aussi quelquefois le Mégacéros) et les os, en particulier les côtes, les diaphyses et métapodes des grands et moyens herbivores, les os longs de différents oiseaux, rongeurs et carnivores, les dents de bovidés, cervidés et les canines d'Ours et Lion des cavernes, de Renard et de Loup, ainsi que l'ivoire de Mammouth. Les coquillages marins et quelques fossiles ont été employés pour la confection d'objets de parure (colliers et pendeloques).

Différentes techniques pour l'obtention des supports ont été attestées au cours d'études récentes menées sur les séries d'outillage osseux de Gargas, des Rideaux, de La Tuto de Camalhot et d'Isturitz (San Juan-Foucher 2004, 2005 ; San Juan-Foucher, Vercoutère 2005 ; Goutas 2003, 2004). Le débitage des supports en os se fait généralement par tronçonnage suivi de rainurage ou d'abrasion/raclage ( $p$. ex. pour la bipartition des côtes utilisées pour les lissoirs) ou selon un schéma de partitions successives (employé sur les métapodes transformés en poinçons ou épingles). Très souvent, les objets sont fabriqués à partir d'os dont la morphologie particulière constitue une sorte de « préforme » (corps de côtes pour les « pioches ", métapodes vestigiels de Cheval et de Renne pour les poinçons, épingles et pendeloques). Pour les pièces d'industrie osseuse peu élaborées, comme les poinçons sur esquille ou les « retouchoirs", le débitage des supports se fait par simple fracturation des diaphyses, suivi d'un façonnage sommaire de la pointe ou de l'utilisation directe des éclats choisis.

Le travail de transformation des bois de cervidés, dont l'acquisition provient autant de la chasse que de la collecte, comprend une première phase d'élagage de la perche au cours de laquelle les andouillers sont dégagés par percussion directe ou par entaillage et flexion (quoique dans certains cas on a pris soin d'utiliser le rainurage bifacial). Les baguettes qui serviront de supports aux outils et armatures sont obtenues soit directement sur la perche, soit sur des sections de perche préalablement tronçonnées, débitées ensuite par double rainurage ou par bipartition. Toutes les données fournies par les différents aspects de ces études indiquent une gestion bien réfléchie de l'économie des ressources animales non alimentaires, en particulier des matières utilisées pour l'équipement de chasse et les outils de base les plus solides (bâtons percés, ciseaux...), alors que les outils courants peu façonnés et facilement remplaçables, sont réalisés à partir de supports prélevés sur les carcasses, au hasard de la chasse.

D'un point de vue typologique, l'équipement osseux des gravettiens pyrénéens se caractérise par un objet emblématique, la « sagaie d'Isturitz » (fig. 9 et 10). Considéré par D. de Sonneville-Bordes $(1971,1972,1988)$ comme « fossile directeur osseux » du Périgordien à burins de Noailles, sa diffusion comprend une vaste zone incluant l'Aquitaine, les Pyrénées centrales, et les deux versants des Pyrénées atlantiques. Dans le cadre territorial de cette synthèse, cette pièce est représentée surtout dans le gisement éponyme (la série d'Isturitz compte 179 pièces recensées, toutes collections confondues), mais plusieurs exemplaires ont été répertoriés dans des niveaux gravettiens d'autres sites : Gargas (6), Les Rideaux (5), Téoulé (2), Les Battuts (10) ${ }^{7}$. Elle a été toujours définie comme une pointe de projectile (Saint-Périer 1949 ; Movius 1973), mais les dernières recherches tendent à montrer qu'il pourrait s'agir d'un ensemble de différents outils et armatures, partageant un aménagement similaire d'extrémité proximale appointée, avec des versions alternatives qui combinent des biseaux, incisions et encoches (San Juan-Foucher, Vercoutère 2005 ; Goutas 2004).

Un autre type d'outil osseux caractéristique de cet horizon chronologique dans les Pyrénées est une variante de ce que A. Leroi-Gourhan (1963) avait appelé les « pioches en côtes d'herbivores ". II s'agit d'une série de tronçons de côtes de grands herbivores, (Bison à la Tuto de Camalhot, grand Boviné - Bison ou Aurochs - à Gargas, alors que les nombreux exemplaires d'Isturitz n'ont pas fait l'objet d'une détermination précise) qui présentent une extrémité active appointée et très usée, parfois esquillée, correspondant à la partie distale anatomique. Sur les deux faces de ces côtes, apparaissent gravées des séries d'incisions parallèles, longues et fines, organisées en groupes réguliers, parfois associés à d'autres séries d'incisions courtes et profondes sur les bords (fig. 11). Des côtes utilisées et incisées sont parfois présentes dans les gisements gravettiens et aurignaciens du sud-ouest français, mais l'ensemble pyrénéen est singulièrement homogène et leur degré de standardisation - alors qu'elles proviennent de gisements distants entre 120 et $230 \mathrm{Km}$ - nous autorise à les considérer comme une sorte de «marqueur» culturel.

Outre ces deux types particuliers, le cortège commun des séries osseuses gravettiennes comprend une grande variété de pointes de sagaie, poinçons, outils biseautés (ciseaux et coins), épingles, bâtons percés, lissoirs et nombreux éléments d'une industrie osseuse peu élaborée, comme les retouchoirs et les côtes utilisées non décorées.

Témoignages artistiques et symboliques : parure, art mobilier et art pariétal

Parmi les objets considérés comme des éléments de parure, certains sont largement diffusés dans la plupart des gisements de l'aire étudiée et ne montrent pas de caractères discriminants par rapport aux corpus des périodes précédentes et suivantes : c'est le cas des perles de collier en segments d'os d'oiseau, des dents et des coquillages perforés, même si dans le registre de ces derniers objets, on peut observer une certaine variabilité chrono-stratigraphique et territoriale, pas toujours imputable aux conditions paléoenvironnementales (Taborin 1993, 2001).

(7) Les chiffres proviennent de notre dernière révision des matériaux de plusieurs séries pyrénéennes (San Juan-Foucher 2004 ; San Juan-Foucher, Vercoutère 2005). 

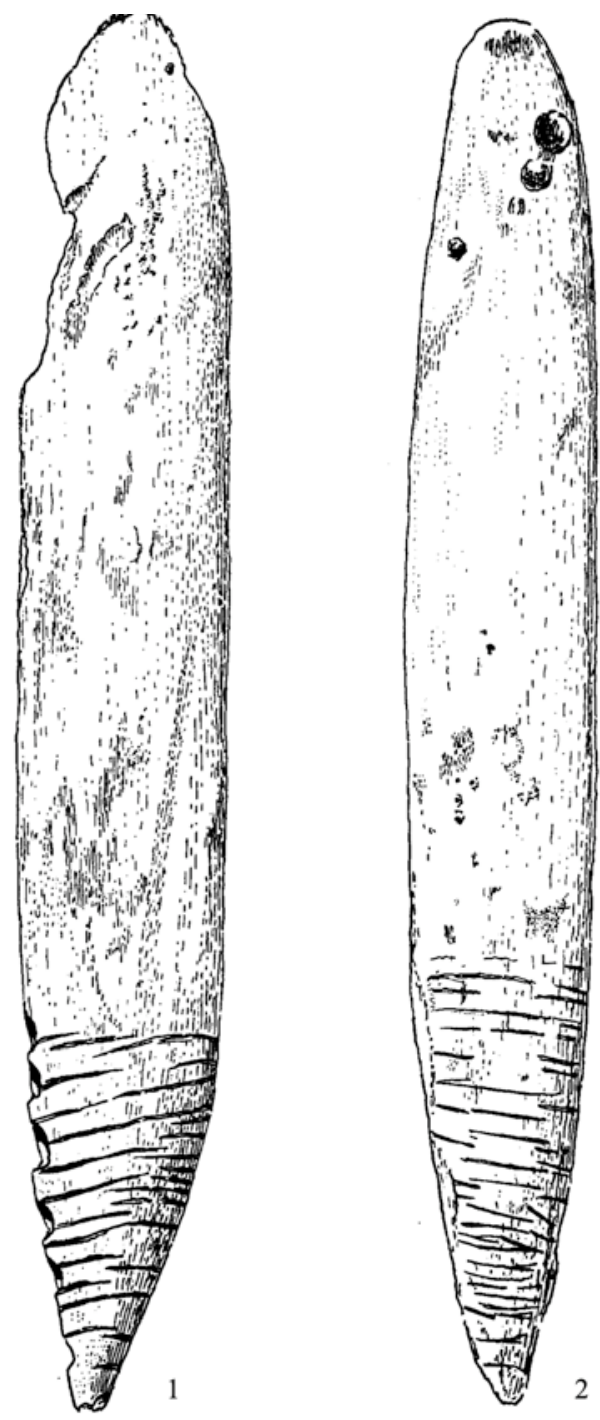

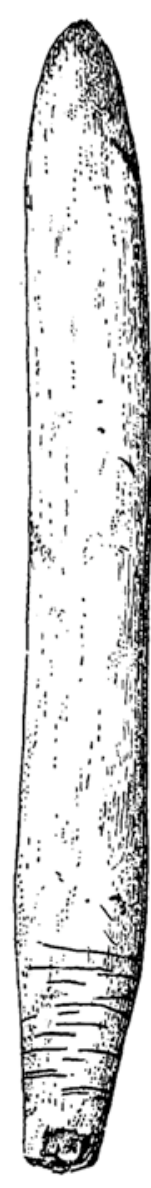

3

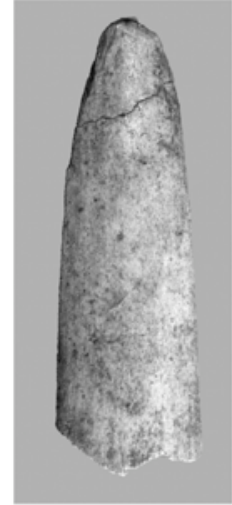

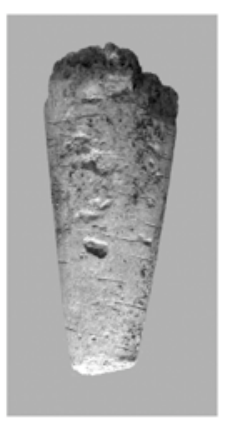

5

0
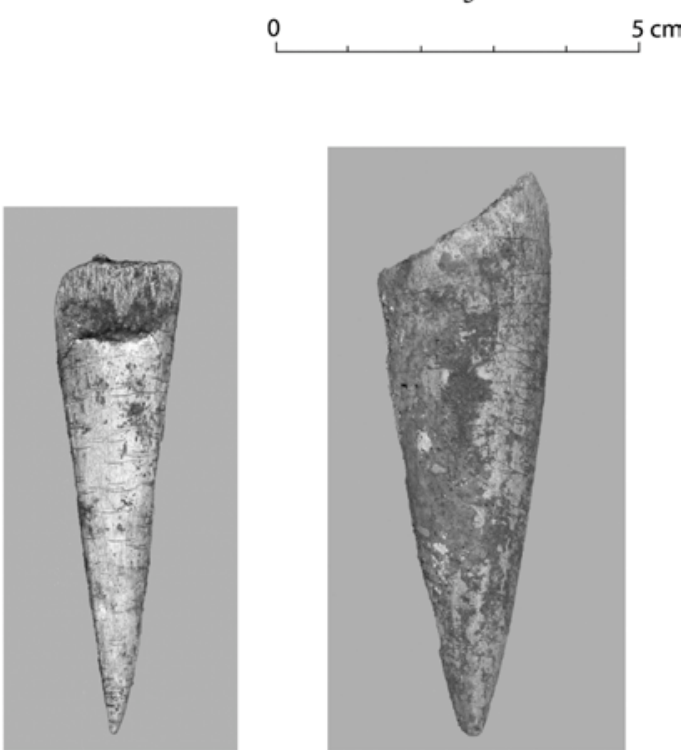

8

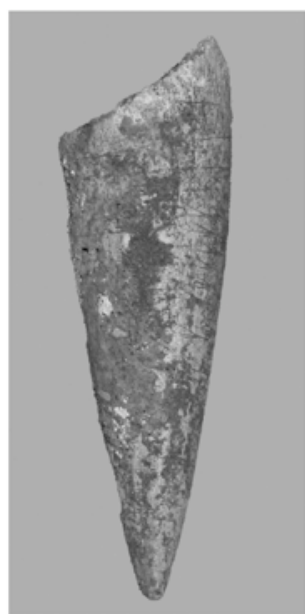

9

Figure 9 - Industrie osseuse : sagaies de type Isturitz. 1 à 3 : Isturitz (Saint-Périer 1952). 4 à 9 : Gargas (clichés San JuanFoucher).

Figure 9 - Bone industry : antler points called "sagaies d'Isturitz".. 1 à 3 : Isturitz (Saint-Périer 1952). 4 à 9 : Gargas (photos San Juan-Foucher). 

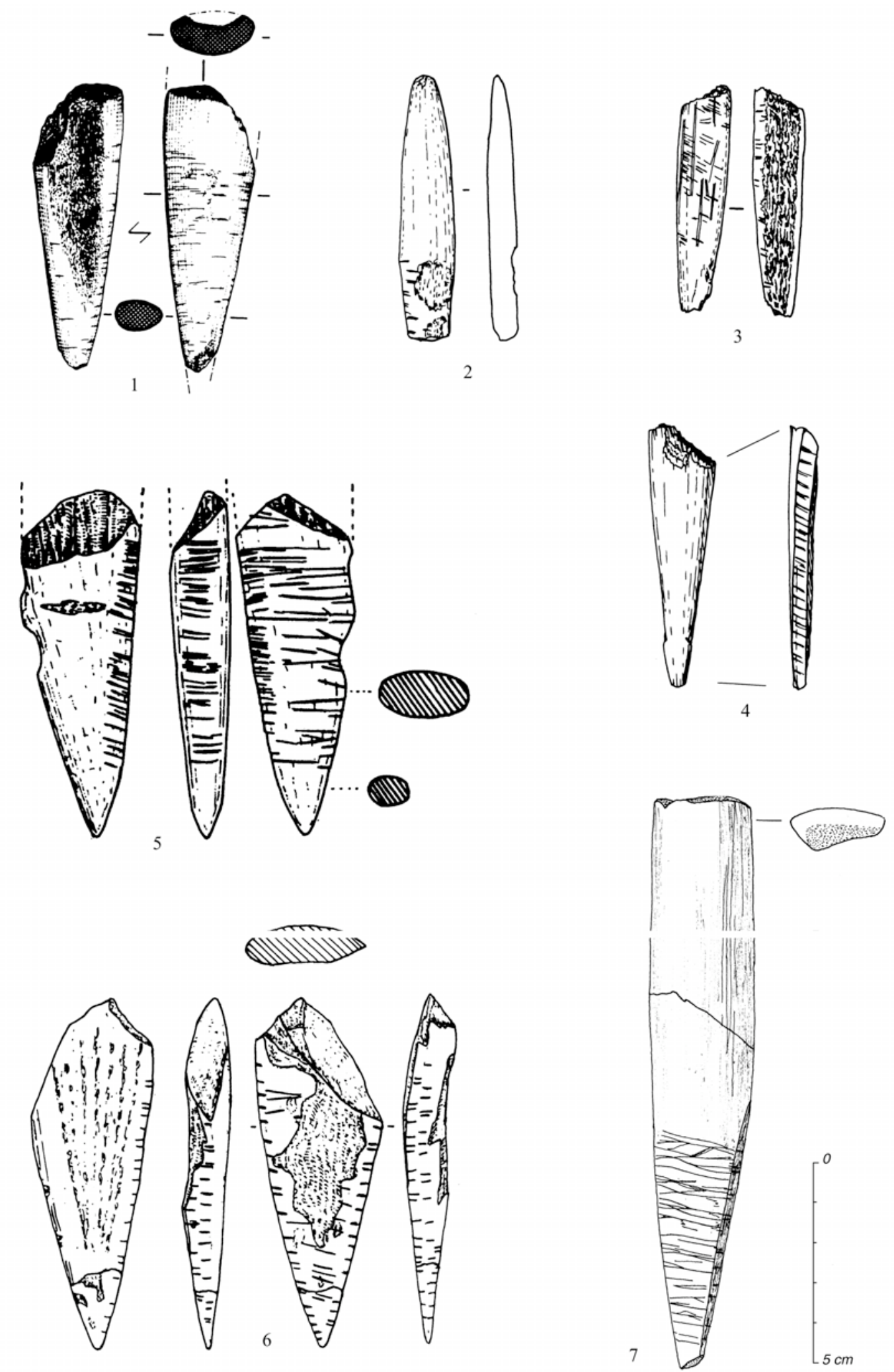

Figure 10 - Industrie osseuse : sagaies de type Isturitz. 1 à 4 : Les Rideaux (1: Allard et Jarry 1993. 2 à 4 : San Juan-Foucher). 5 : Usategui et 6 : Bolinkoba (Corchón 1986). 7 : Aitzbitarte III (Mugica 1983).

Figure 10 - Bone industry : antler points called "sagaies d'Isturitz". 1 à 4 : Les Rideaux (1 : Allard et Jarry 1993. 2 à 4 : San Juan-Foucher). 5 : Usategui et 6 : Bolinkoba (Corchón 1986). 7 : Aitzbitarte III (Mugica 1983). 

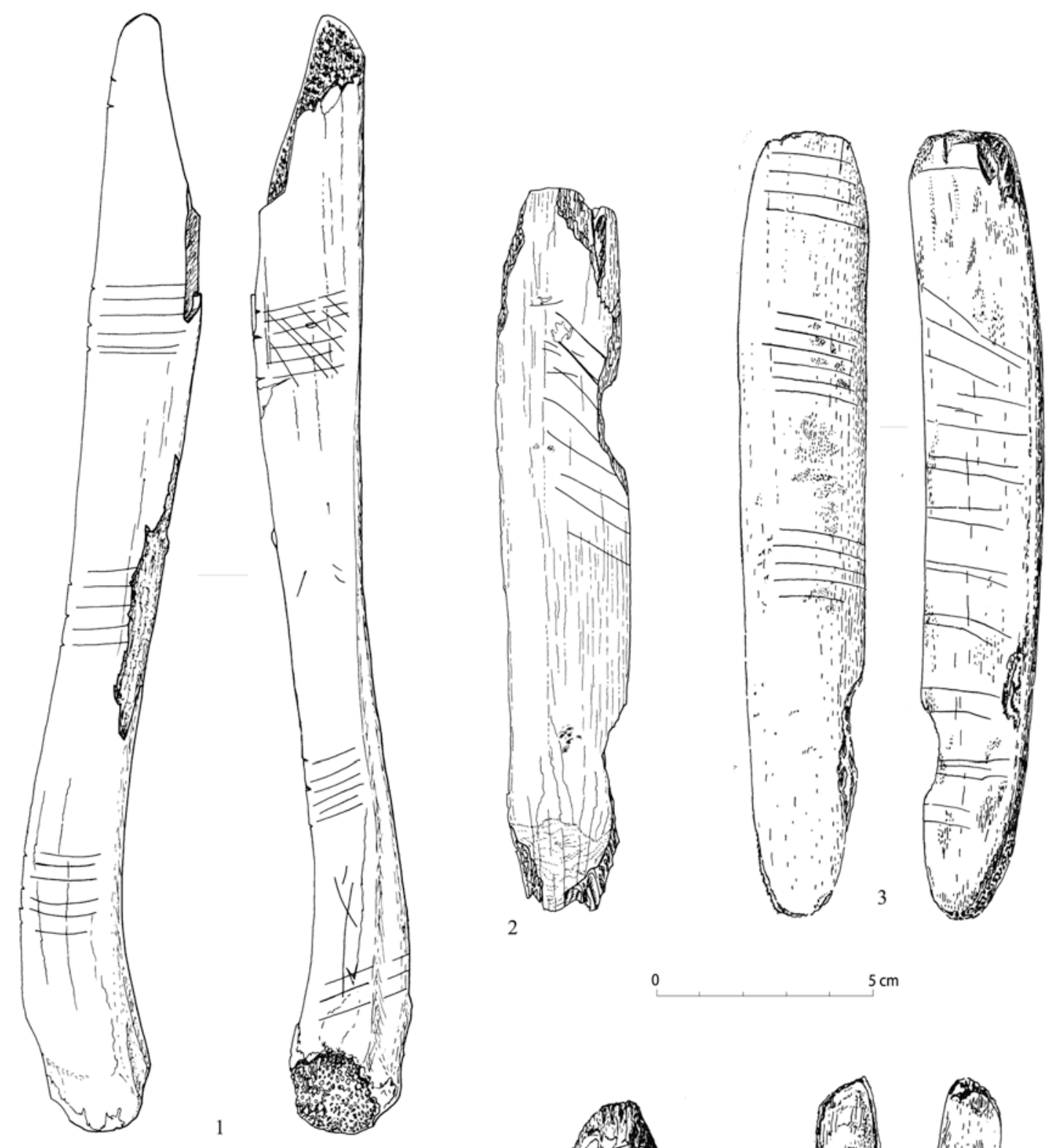

0 $5 \mathrm{~cm}$
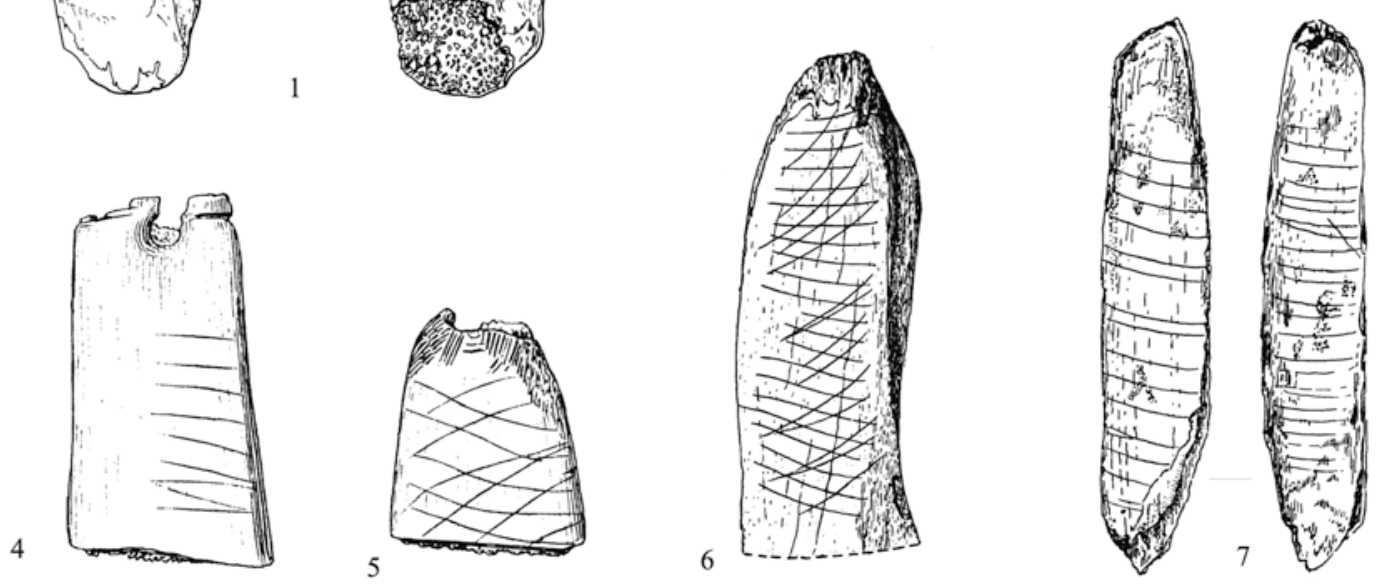

Figure 11 - Industrie osseuse : côtes utilisées et gravées. 1, 2 : Gargas (San Juan-Foucher 2006). 3, 6 et 7 : Isturitz (Saint-Périer 1952). 4, 5 : Tuto de Camalhot Vézian 1966).

Figure 11 - Bone industry : used and engraved ribs. 1, 2 : Gargas (San Juan-Foucher 2006). 3, 6 et 7 : Isturitz (Saint-Périer 1952). 4, 5 : Tuto de Camalhot Vézian 1966). 
Les dents perforées des niveaux gravettiens de Gargas et d'Isturitz proviennent en général des animaux chassés pour leur apport en viande et en fourrure (Cerf ${ }^{8}$, Boviné, Cheval, Renard, Loup), mais dans certains cas, comme pour la Hyène, le Blaireau, l'Ours et le Lion des cavernes, les canines ont été certainement prélevées sur des crânes d'animaux trouvés dans les galeries des grottes.

Un cas particulier est celui des coquillages percés trouvés dans les sites pyrénéens, nécessairement apportés au cours de déplacements de moyenne et longue durée. Que ce soit à Isturitz ou à Gargas, l'apport de coquillages est fondamentalement atlantique ${ }^{9}$, ce qui semble évident pour le premier site mais pas pour le deuxième, situé au pied de la zone centrale de la chaîne. Cette information est significative en termes de vecteur de déplacement et d'espace culturel (Foucher 2006 ; San Juan - Foucher, Foucher, à paraître).

Des objets d'ornement personnel plus originaux et élaborés se retrouvent dans la majorité des gisements pyrénéens, combinant à la fois des techniques partagées, acquises au cours du façonnage des outils, et l'esprit créatif individuel de leurs auteurs gravettiens. On peut citer parmi les plus beaux exemples les bandeaux en ivoire décorés de motifs incisés en zigzag de la grotte du Pape à Brassempouy (Thiault 2001) ; parfois, l'imagination s'associe à un certain sens pratique pour remployer des fragments d'autres objets, c'est le cas des pendeloques de «deuxième intention» de la Tuto de Camalhot (fig. $11: 4,5$ et fig. $12: 2$, 3) Vézian 1966 ; San Juan-Foucher 2006) prélevés sur une côte de Bison incisée, et de ceux du niveau III d'Isturitz (fig. $12: 4,5$ ), qui mettent à profit les biseaux à incisions profondes des fragments de sagaies récupérés après cassure (Saint-Périer 1952 : 59, fig. 26 et pl. IV). L'attribution chronologique de ces dernières est toutefois à revoir (Solutréennes ?). Des pendeloques sur support lithique, obtenues à partir de petits galets incisés et perforés, sont aussi répertoriées dans les séries gravettiennes d'Isturitz.

II faut mentionner ici un type d'objets particuliers qui ne peut pas être classé parmi la parure personnelle, même s'il bénéficie des mêmes techniques de fabrication, mais qui appartient au registre privilégié et limité des artefacts nous renseignant sur le domaine des activités ludiques et/ou symboliques des Gravettiens. II s'agit des fragments de flûtes en os d'Isturitz (Saint-Périer 1952 ; Buisson 1990), dont les exemples se rapprochent des pièces aurignaciennes de Geissenklösterle, dans le Jura souabe (Hahn 1999).
Quant à l'art mobilier sur matières dures organiques, peu de nouveautés sont à ajouter à la synthèse réalisée par $D$. Sacchi en 1987 lors de sa communication au colloque de Foix (1990). Les objets les plus exceptionnels (et rares !) restent toujours les statuettes féminines de Brassempouy, une dizaine en comptant les exemplaires complets et les fragments (Delporte 1995), et la «Vénus» de Lespugue, trouvée par R. et S. de Saint-Périer lors des fouilles de la grotte des Rideaux (Saint-Périer 1922). Les seules gravures figuratives sur os connues dans le Gravettien pyrénéen depuis un demi-siècle étaient celles du niveau IV d'Isturitz, représentant un cheval et un arrière-train de Bovidé sur les deux faces d'une côte (fig. 12 : 1), ainsi que deux figures schématiques ovales considérées comme des poissons (SaintPérier 1952 : fig. 87). Au cours d'une récente révision du matériel des fouilles Cartailhac-Breuil de Gargas (Foucher, San Juan 2002), une nouvelle figuration gravée (probablement un poisson) a été trouvée sur un fragment d'os de grand Cervidé. Une dent d'ours gravée de séries de longs traits incisés sur chaque face (fig. $12: 6$ ) a été aussi découverte à l'occasion de la même étude.

Finalement, nous pouvons citer ici plusieurs exemples d'outils décorés de motifs qui ne semblent pas être «utilitaires». C'est le cas des côtes incisées d'Isturitz, Gargas et La Tuto de Camalhot mentionnées plus haut comme pièces caractéristiques (fig. 11), d'un «poussoir» de ce dernier gisement orné d'un motif géométrique (Vézian 1966), et d'un lissoir incisé en forme de poisson stylisé du niveau IV d'Isturitz (fig. 12 : 7) (Saint-Périer 1952 : fig. 75). En ce qui concerne les objets de la grotte des Rideaux, que R. de Saint-Périer considérait associés à la "Vénus» en particulier la célèbre «spatule aux serpents» (1924), une révision de la collection est actuellement en cours (San JuanFoucher 2004) pour permettre d'affiner l'attribution de la série, dans laquelle existent certainement des mélanges intervenus au cours des fouilles.

L'art mobilier sur support lithique tient une place importante dans l'expression artistique (et symbolique) des gravettiens pyrénéens. À Isturitz, sont répertoriés plus d'une trentaine de galets ou de plaquettes ornés d'une iconographie typiquement paléolithique (fig. $13: 2$ à 6), composée d'anthropomorphes, de signes variés, de mammouths, de chevaux, de cervidés et de bovidés (SaintPérier 1952). À Gargas, on connaissait principalement le galet en schiste publié par $\mathrm{H}$. Breuil ${ }^{10}$ gravé d'une composition associant un bison et un lion avec d'autres traits non

(8) Les dents de Cerf sont bien documentées à Gargas et à Isturitz mais, en revanche, aucune dent de Renne ne figure dans les deux séries.

(9) Les espèces identifiées sont : Littorina obtusata (la plus abondante), Littorina littorea, Semicassis saburon, Thaïs haemastoma, Sipho sp., Cardium sp., Pecten maximus, Chlamys islandica, Cymia calcarata, Latrunculus eburnoïdes, Neptunea dextre, Nucella lapillus, Patella sp., pour Isturitz (Taborin 1993); Littorina obtusata, Littorina littorea, Nucella lapillus, Patella vulgata, Trivia europea., Pecten sp., pour Gargas (Foucher, San Juan 2004, Foucher 2005, San Juan-Foucher, Foucher à paraître)

(10) Dans sa publication de 1953, H. Breuil propose les relevés de trois autres plaquettes : la première est gravée recto verso de traits non intelligibles, la deuxième de pattes de "Chevreuil» et la troisième d'une tête de "taureau»; ces deux dernières plaquettes n'ont pas été retrouvées. 

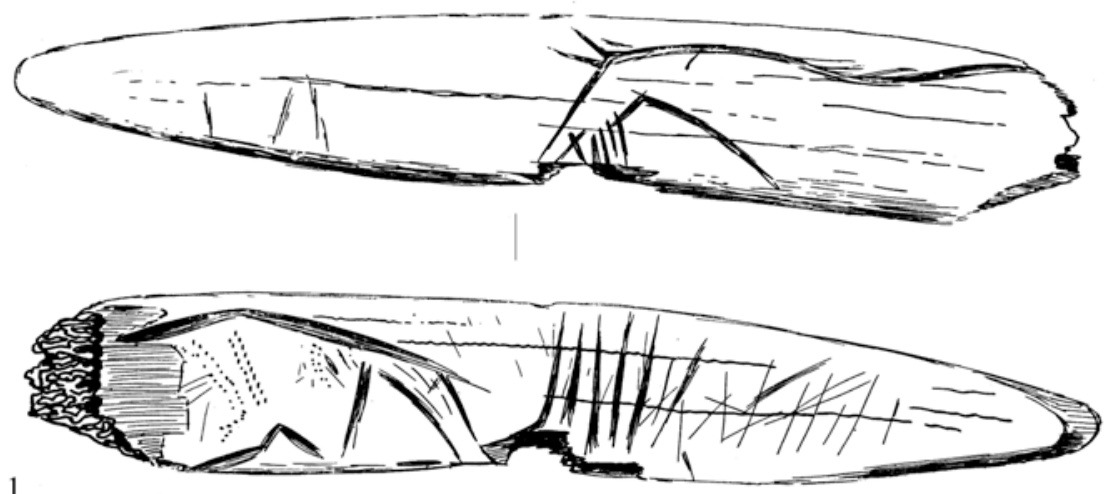

1
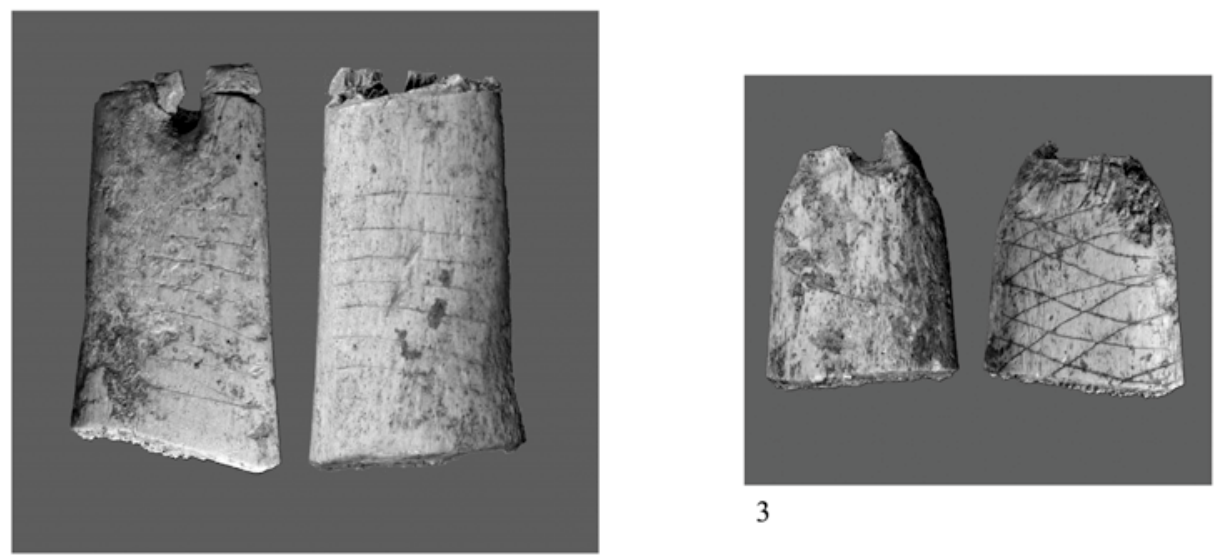

3

2

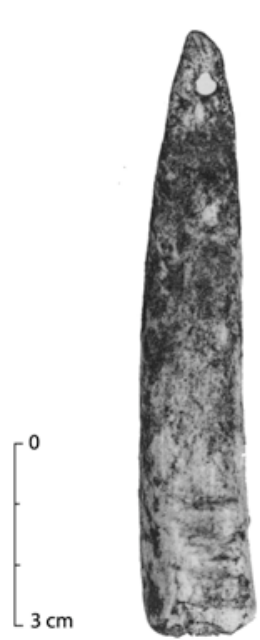

4

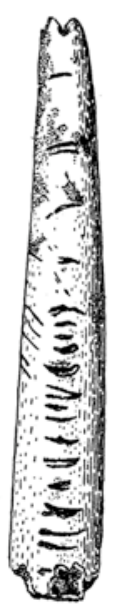

5

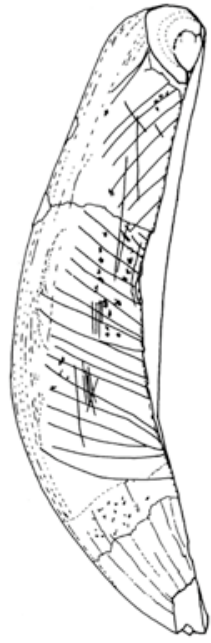

6

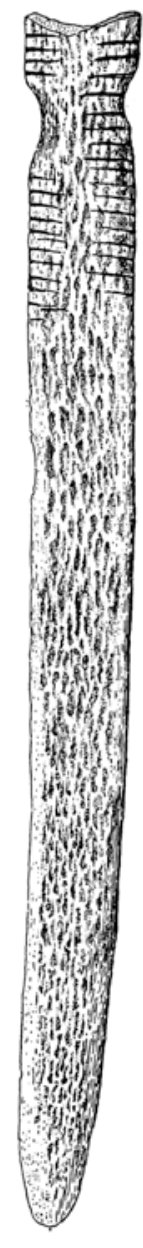

7

Figure 12 - Parures et art mobilier. 1,4,5,7 : Isturitz (Saint-Périer 1952). 2, 3 : La Tuto de Camalhot (clichés P. Foucher). 6 : Gargas (dessins C. San Juan).

Figure 12 - Body ornamentation and mobiliary art. 1,4,5,7 : Isturitz (Saint-Périer 1952). 2, 3 : La Tuto de Camalhot (photos P. Foucher). 6 : Gargas (drawings C. San Juan). 

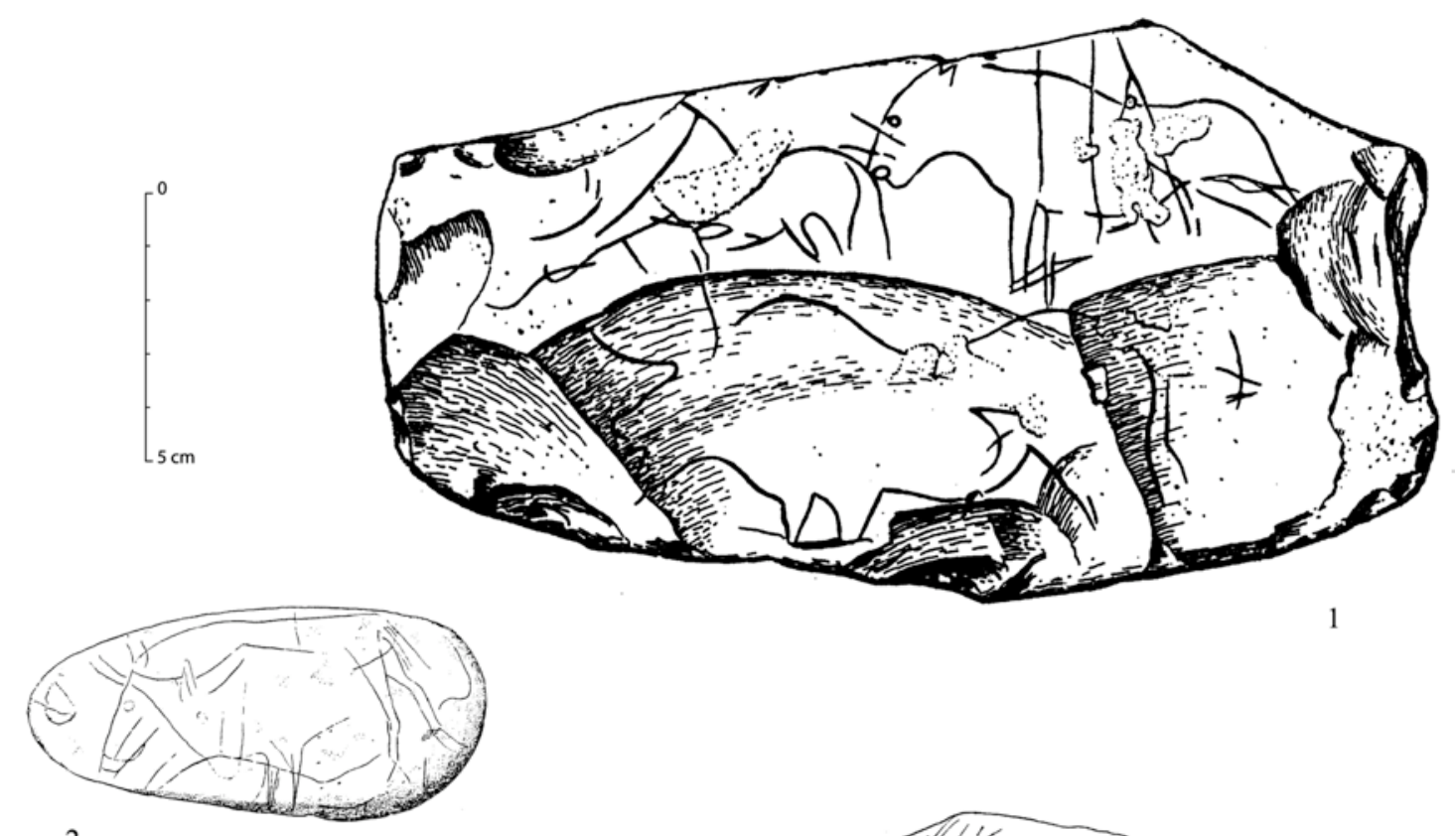

2
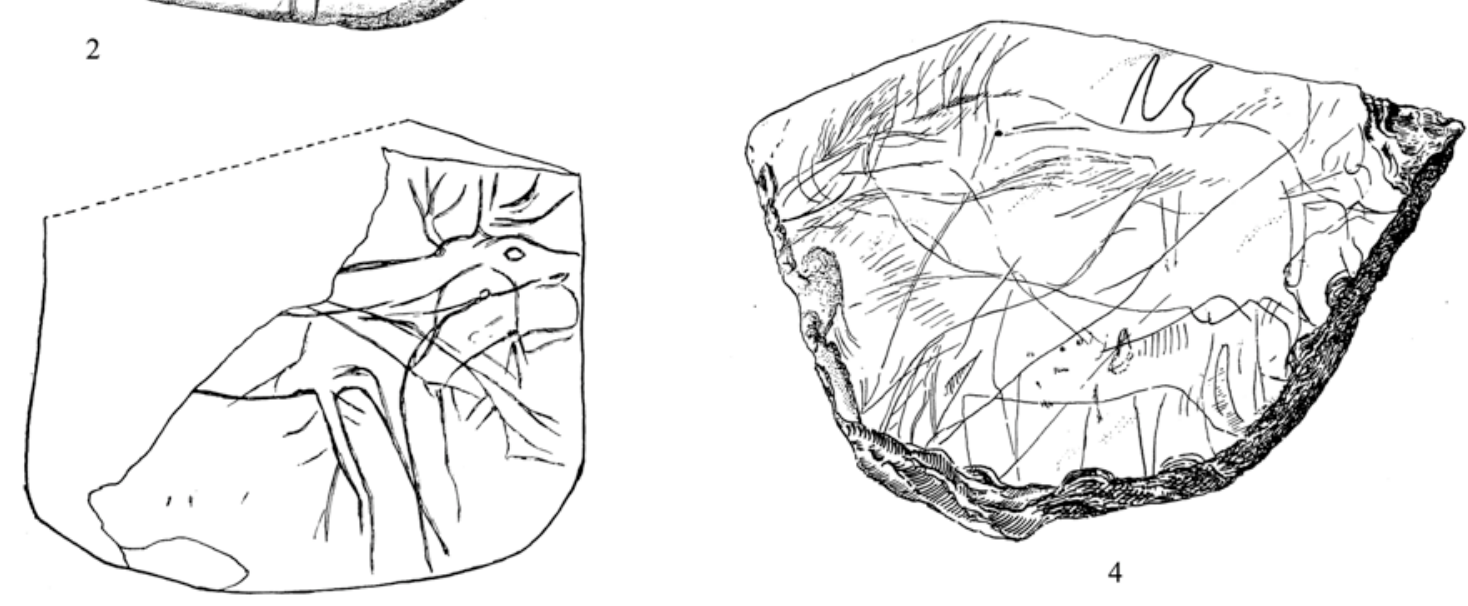

3
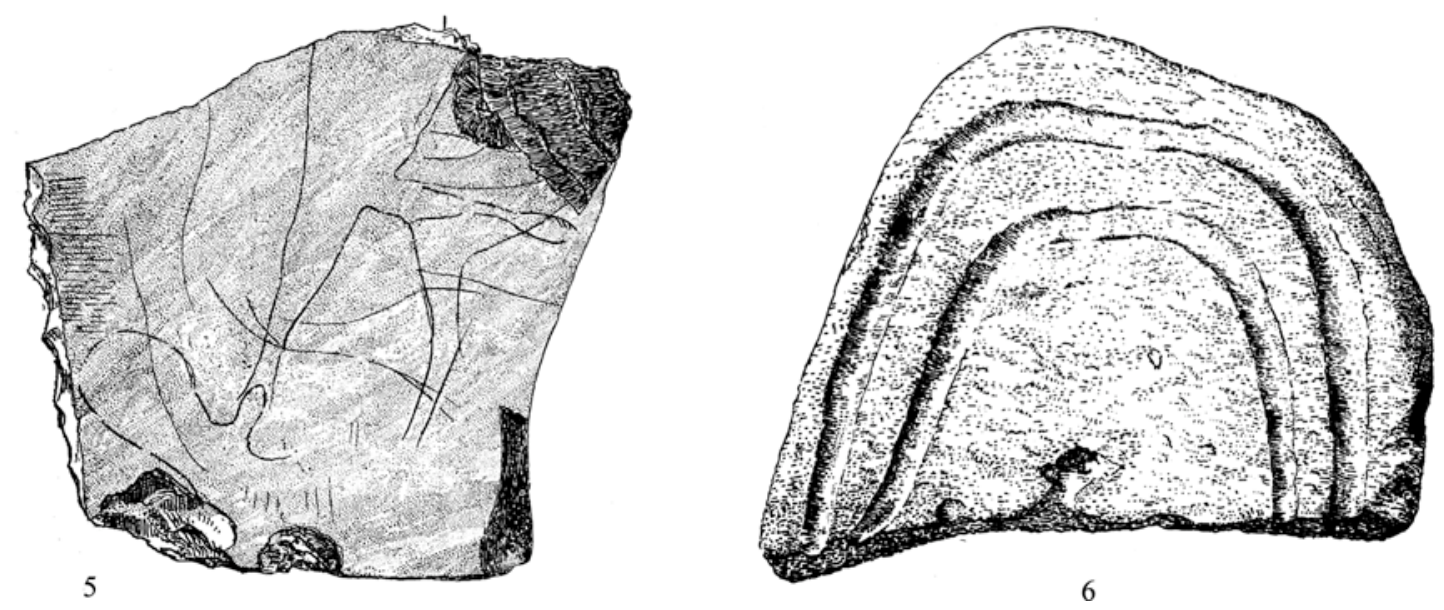

Figure 13 - Art mobilier sur support lithique. 1 : Gargas (Breuil 1953). 2 à 6 : Isturitz (Saint-Périer 1952).

Figure 13 - Mobiliary art. 1 : Gargas (Breuil 1953). 2 à 6 : Isturitz (Saint-Périer 1952). 


\begin{tabular}{|c|c|c|c|c|}
\hline 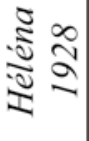 & 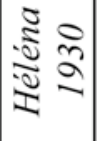 & 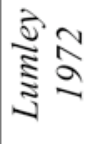 & 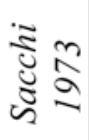 & Archéostratigraphie \\
\hline $\mathrm{A}$ & 1 & 1 & 1 & Vestiges protohistoriques \\
\hline B & 2 & 2 & 2 & $\begin{array}{l}\text { Chasséen } \\
\text { Epicardial }\end{array}$ \\
\hline \multirow{2}{*}{$\mathrm{C}$} & 3 & 3 & 3 & Azilien terminal ? \\
\hline & 4 & \multirow{2}{*}{$\begin{array}{l}4^{1} \\
4^{2}\end{array}$} & 4 & Azilien \\
\hline $\mathrm{D}$ & & & 5 & Magdalénien supérieur \\
\hline$(\mathrm{L})$ & & \multirow{4}{*}{$5^{1}$} & 6 & \\
\hline $\mathrm{E}$ & & & 7 & Gravettien \\
\hline$(\mathrm{L})$ & & & 8 & \\
\hline$(\mathrm{S})$ & & & 9 & \\
\hline $\mathrm{F}$ & 5 & $5^{2}$ & 10 & Aurignacien typique \\
\hline (L) & 6 & 6 & 11 & Moustérien paracharentien \\
\hline \multirow{3}{*}{ G } & 7 & 7 & 12 & Moustérien paracharentien \\
\hline & & \multirow{2}{*}{8} & 13 & \\
\hline & 8 & & 14 & Moustérien paracharentien \\
\hline$(\mathrm{L})$ & & & 15 & \\
\hline
\end{tabular}

Figure 14 - Grotte de la Crouzade (Aude) : interprétation archéostratigraphique. $(L)=$ limon, $(S)$ cailloutis, grisé = dépôt archéologiquement stérile.

Figure 14 - Crouzade cave (Aude) : stratigrafic interpretation. $(L)=$ silt, (S) = gravel, gray = archaeologically barren deposit.

figuratifs (1953) ; bien datée par son niveau stratigraphique de provenance, cette pièce (fig. $13: 1$ ) joua un rôle considérable dans les processus de datation de l'art pariétal de Gargas - et gravettien en général - en raison de la forte identité stylistique entre le bison de la plaquette et ceux gravés sur les parois de la galerie inférieure. Quatre nouveaux supports lithiques gravés ont été découverts dans le cadre de la révision de la collection Cartailhac-Breuil ; on a pu y déchiffrer une tête de cheval, des têtes d'animaux indéterminés, un signe triangulaire, des traits non figuratifs (San Juan, Foucher à paraître).

L'art pariétal gravettien des Pyrénées est actuellement connu dans trois sites répartis sur la partie centre-occidentale de la chaîne : Gargas, Les Trois-Frères et Erberua.

L'ensemble pariétal de Gargas (galerie inférieure), composé de 230 empreintes de mains peintes en négatif, déclinant de nombreuses formules aux doigts repliés ou manquants, et de plusieurs panneaux gravés de motifs animaliers, a fait l'objet de nombreuses études (Breuil 1952 ; Salhy 1963 et 1969 ; Leroi-Gourhan 1967 ; Clot 1973 ; Barrière 1976 ; Groenen 1988, Foucher et al. 2007). La date ${ }^{14} \mathrm{C}$ de 26860 $\mathrm{BP} \pm 460$, réalisée à partir d'un os fiché dans une fissure d'un des panneaux aux mains peintes, fixe un cadre gravettien indirect à son art pariétal (Clottes et al. 1992), et confirme la première attribution de $\mathrm{H}$. Breuil mentionnée plus haut.
La grotte des Trois-Frères, plus connue par ses manifestations pariétales magdaléniennes, possède néanmoins deux galeries vraisemblablement ornées par les Gravettiens : la Galerie des Chouettes et la Galerie des Mains (Bégouën, Breuil 1958 ; Bégouën, Clottes 1984). Ces représentations gardent sans doute une relation étroite avec l'occupation gravettienne d'Enlène-EDG, puisque les deux cavités appartiennent au même réseau karstique et communiquent entre elles.

La grotte d'Erberua, correspondant au réseau inférieur toujours actif d'Isturitz, présente un dispositif orné très diversifié. Bien que les auteurs de la monographie le rapprochent des sanctuaires magdaléniens pyrénéens dans une étude préliminaire (Larribau, Prudhomme 1984, Prudhomme 1987), l'existence de trois mains négatives suggère également la chronologie gravettienne d'une partie de son art pariétal.

\section{Le paléo-environnement}

Les études palynologiques ont été peu développées pour cette période ; on peut citer toutefois les travaux dirigés par G. Jalut qui n'abordent que la fin du Gravettien, à partir de 21000 BP (Jalut et al. 1982, 1996). Quant à l'étude de la faune, il faut d'abord se reporter aux études 
anciennes et très succinctes. À Gargas ${ }^{11}$, les bovinés (bisons, aurochs) sont une fois et demi plus nombreux que les cervidés (cerf, renne), le Chamois étant la quatrième espèce chassée (Bouchud 1958). Á Isturitz, Cheval et Renne sont les espèces les plus abondantes, suivies des cervidés ; on remarquera la présence d'espèces froides : le Mammouth, le Rhinocéros à narines cloisonnées, le Harfang des Neiges et le Renard bleu (Saint-Périer 1952).

Des études plus récentes faites à Enlène-EDG démontrent que les gravettiens ont occupé la grotte à la mauvaise saison et chassé, de manière sélective, le Renne et les grands Bovidés (Fosse 1992). À La Carane-3, les Caprinés et les Cervidés sont les espèces les plus chassées (Foucher, San Juan, Martin 2000), alors que les Gravettiens de la Tuto de Camalhot ont privilégié le Bison (Lignereux, Vézian à paraître)

On constatera que le spectre faunique est très diversifié, mais il est encore trop tôt pour savoir à quoi il correspond précisément et quelle peut être la part revenant aux variations climatiques, à l'environnement proche des sites (montagne, piémont, plaine) ou aux pratiques cynégétiques. Au bout du compte, le paléo-environnement au Gravettien dans les Pyrénées atlantiques et centrales reste encore très peu documenté.

\section{Les Pyrénées méditerranéennes (D. S.)}

L'occupation gravettienne n'a, semble-t-il, laissé que peu de traces dans la partie méditerranéenne de l'aire pyrénéenne largo sensu. Les quelques données disponibles concernent la limite orientale de la zone sous-pyrénéenne, précisément le massif de la Clape, et, au-delà, la vallée de la Cesse, affluent senestre du cours inférieur de l'Aude. Dans le premier secteur, la documentation provient de la grotte de la Crouzade (Aude) ; dans le second, elle est issue de la Petite grotte de Bize (Aude).

\section{Grotte de la Crouzade (Aude)}

C'est à Th. Héléna que revient le mérite d'avoir, le premier, relevé la présence de pointes de La Gravette à La Crouzade. Elles gisaient dans un niveau attribué à l'Aurignacien " immédiatement au-dessus et en contact avec le Moustérien (...) à 3 et 4 mètres de profondeur, [il] forme une couche de dépôts de $0,50 \mathrm{~m}$ à 1 mètre d'épaisseur, nettement séparés des premiers foyers magdaléniens par une couche stérile de sable et de petits cailloux roulés de près d'un mètre de puissance... » (Th. Héléna 1924). Dans sa description détaillée de la stratigraphie,
Ph. Héléna (1928), subdivise en deux l'horizon aurignacien mis au jour par son père. II distingue ainsi un niveau $F$, qualifié d'aurignacien moyen (ancêtre taxinomique de l'Aurignacien typique), et un niveau $\mathrm{E}$, rapporté à l'Aurignacien supérieur (le Périgordien supérieur de $D$. Peyrony) ${ }^{12}$. Cette dernière strate prend la forme d'une " très mince ligne de cendres " traversant "vers le haut, et en certains points seulement » des "dépôts naturels de limon jaune stérile » (fig. 14). Les séries lithiques, numériquement faibles, conservées au Musée archéologique de Narbonne, s'accordent bien, typologiquement parlant, à ce schéma archéostratigraphique (Sacchi 1973, 1981, 1986). L'industrie du niveau $F(N=58)$ ou couche 10 (fig. 14) offre tous les caractères d'un Aurignacien sans doute ancien ; celle du niveau $\mathrm{E}(\mathrm{N}=24)$ ou couche 7 (fig. 14) évoque précisément le Gravettien avec quelques pointes de la Gravette, et des lamelles à bord abattu (fig. $15: 1,3,4,6-9$ ). Des objets de parure s'y associaient (croches de cerf et incisive de cheval perforées). Le Renne, prédominant, le Bœuf, le Cheval, le Cerf forment l'essentiel des espèces chassées selon Ph. Héléna (1928).

De son côté, E. Genson signale laconiquement les " sérieuses et minutieuses fouilles », exécutées en collaboration avec J.-S. Albaille ; elles permirent " de relever de bonnes coupes stratigraphiques et de constater la présence de foyers (...) aurignaciens » (Genson 1937). Le matériel recueilli figurait autrefois dans les vitrines du Musée du Vieux Biterrois, sous la mention " couche $n^{\circ} 2$ en place, Aurignacien » (Sacchi 1986). En plus des pièces de facture aurignacienne, il comporte une composante d'allure nettement gravettienne : pointe de La Gravette, microgravette, fragment de fléchette (fig. $15: 2,5,10$ ).

Rappelons en outre que le produit mêlé des fouilles exécutées en 1874 par Th. Rousseau, puis, la même année, par F. Bru pour le compte de la Commission archéologique de Narbonne, recèle également quelques pointes de la Gravette et une microgravette (Sacchi 1982, 1986).

\section{Petite grotte de Bize (Aude)}

II est désormais acquis depuis bientôt quarante ans (Sacchi 1969), que la couche 1 du profil stratigraphique décrit par Ph. Héléna (1934) n'appartient pas à « l'Aurignacien supérieur », comme celui-ci l'affirmait, mais au Badegoulien. La pointe de La Font-Robert, mentionnée par le préhistorien narbonnais, relève très vraisemblablement d'une erreur d'interprétation typologique ${ }^{13}$. Cependant, une armature inédite (fig. $15: 11$ ), conservée à I'Université Paul Valéry de Montpellier, accrédite l'existence de pointes de La Gravette « au fond du vestibule [dans]

(11) La faune des fouilles Cartailhac-Breuil du niveau gravettien fait actuellement l'objet d'une nouvelle révision Vercoutère 2005) qui pourrait apporter des informations plus nuancées.

(12) Philippe Héléna demeurera toujours fidèle à la nomenclature de H. Breuil, et bien après que D. Peyrony en ait opéré la dislocation et la refonte.

(13) Reprenant, sans les vérifier, les affirmations de Ph. Héléna, Louis Méroc accrédita l'existence d'un " niveau à pointe du type de la Font-Robert » dans la Petite grotte de Bize (Méroc 1963). 

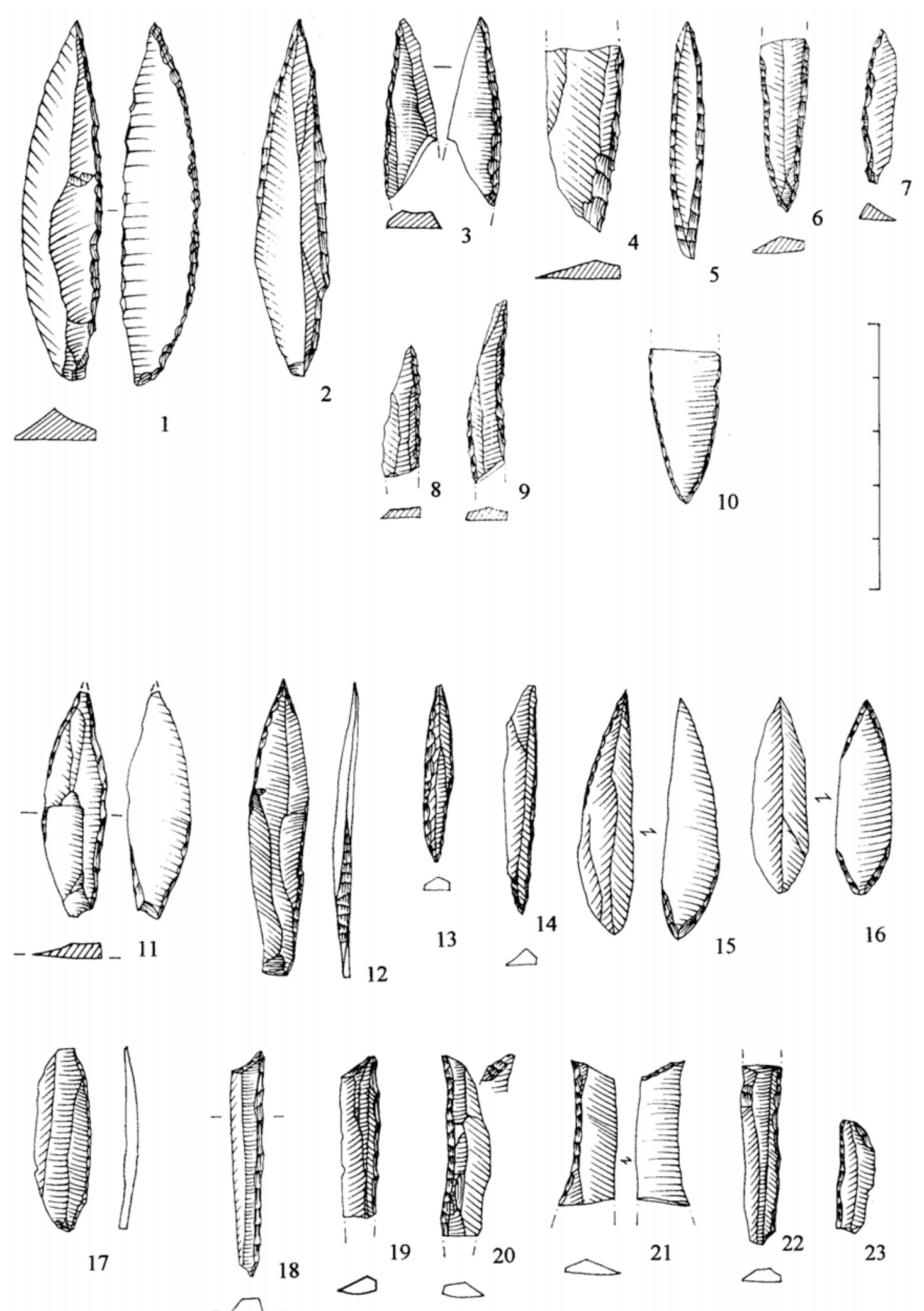

Figure 15 - Éléments caractéristiques de l'industrie lithique du Gravettien des Pyrénées méditerranéennes. 1 à $10=$ grotte de la Crouzade (Aude), couche $7 ; 11$ à 23 = Petite grotte de Bize (Aude).

Figure 15 - Characteristic elements of the Gravettian lithic industry in the Mediterranean Pyrenees. 1 à $10=$ Crouzade cave (Aude), layer $7 ; 11$ à 23 = Petite grotte de Bize (Aude). 
un passage très bas donnant accès vers l'extérieur (...) au niveau le plus inférieur » (Héléna 1932). Mais ce sont les matériaux recueillis par E. Genson qui contiennent les éléments les plus significatifs d'une présence gravettienne dans la Petite grotte de Bize. Ils prennent la forme d'une pointe de la Gravette, d'une microgravette, de fléchettes et de lamelles à bord abattu, dont plusieurs exemplaires tronqués (fig. $15: 12$ à 23). Toutefois, ces objets étiquetés " couche inférieure $n^{\circ} 6$, Solutréen » dans le dispositif mis en place au Musée du Vieux Biterrois par l'auteur des fouilles ${ }^{14}$, se mêlent à des pointes à cran méditerranéennes et autre pointe foliacée solutréenne. L'hétérogénéité de cet ensemble ne fait donc aucun doute.

Les informations relatives au Gravettien dans la partie orientale de la région nord-pyrénéenne procèdent intégralement de fouilles antérieures à la seconde guerre mondiale pour les plus récentes d'entre elles. L'indigence des séries, non exempte de mélanges, l'absence de données contextuelles, ne permettent guère de préciser l'âge et l'identité du faciès concerné. On notera néanmoins que la présence de fléchettes et l'absence de burins de Noailles, suggèrent que l'industrie lithique des deux sites recensés relève vraisemblablement d'un stade ancien de la forme occidentale de cette culture.

\section{CONCLUSION}

Le panorama sur le Gravettien des Pyrénées reste encore très contrasté, en raison du poids des découvertes anciennes, de l'état de la documentation très hétérogène, ainsi que de l'avancement des recherches actuelles. Néanmoins, on peut constater que les zones atlantique et centrale présentent une très forte unité culturelle, tant du point de vue de la culture matérielle et technique, que des manifestations symboliques. Par ailleurs, on observe un réseau de sites très diversifiés (haltes de chasse, sites d'habitat prolongé, sites ornés...) et assez bien répartis sur toute cette aire géographique. Dans ce contexte, les Pyrénées orientales semblent être en marge de cet espace culturel - elles se distinguent notamment au niveau de l'industrie lithique, par la présence de fléchettes, inconnues au centre et à l'ouest de la chaîne - mais les données sur cette dernière région sont bien trop maigres pour en tirer des conclusions définitives.

\section{BIBLIOGRAPHIE}

AGUIRRE M. 2000 - El paleolítico de Antoliñako Koba (Gautegiz-Arteaga, Bizkaia) : secuencia estratigráfica y dinámica industrial. Avance de las campañas de excavación 1995-2000, Illunzar, 4, p. 39-81.

ALLARD M. et JARRY M. 1993 - Collection R. et S. de Saint-Périer à Saint-Gaudens (Haute-Garonne), Préhistoire ariégeoise, Bulletin. de la Société préhistorique AriègePyrénées, XLVIII, p. 47-83, 20 fig.

ALTUNA J. 1990 - La caza de herbívoros durante el Paleolítico y Mesolítico del País Vasco, Munibe (Antropologia - Arkeologia), 42, p. 229-240.

ALTUNA J. 1992a - El medio ambiente durante el Pleistoceno Superior en la región Cantábrica con referencia especial a sus faunas de mamíferos, Munibe (Antropologia - Arkeologia), 44, p. 13-29.

ALTUNA J. 1992b - Dataciones de radiocarbono para el Perigordiense Superior del País Vasco, Munibe (Antropologia - Arkeologia), 44, p. 31-32.

ALTUNA J. 2002 - Cueva de Aitzbitarte III (Errenteria), Arkeoikuska, 2001, p. 128-130.

ALTUNA J., BALDEÓN A., MARIEZKURRENA K. (dir.) 1990 La cueva de Amalda (Zestoa, País Vasco). Ocupaciones paleoliticas y postpaleolíticas, Fundacíon José Miguel de Barandiarán, San Sebastián, 276 p. (Colección Barandiarán : 4).

ARANZADI T. et BARANDIARÁN J. M. 1935 - Exploraciones en la caverna de Santimamiñe (Basondo, Cortezubi). $3^{a}$ Memoria. Yacimiento aziliense y paleolíticos, Bilbao.

ARESO P., ARANZASTI M., OLASKOAGA M., URIZ A. 1990 - Sedimentología de la cueva de Amalda, in : Altuna J., Baldeón A., Mariezkurrena K. (dir.) - La Cueva de Amalda (Zestoa, País Vasco). Ocupaciones paleolíticas y postpaleolíticas, Fundacíon José Miguel de Barandiarán, San Sebastián, p. 33-48. (Colección Barandiarán : 4).

ARRIZABALAGA A. 1995 - La industria lítica del Paleolítico Superior Inicial en el Oriente Cantábrico. Tesis Doctoral. Univ. País Vasco, 1000 p.

ARRIZABALAGA A. 1998a - La gestación de la Prehistoria europea : el ejemplo del Paleolítico superior inicial en el sudoeste francés, Antoine d'Abbadie y su época, Congreso Internacional, Eusko Ikaskuntza-Euskaltzaindia, Donostia, p. 95-116.

ARRIZABALAGA A. 1998b - El aprovisionamiento en materias primas líticas durante la génesis del Leptolítico: El Cantábrico Oriental, Rubricatum, 2, p. 97-104.

ARRIZABALAGA A. et IRIARTE M. J. 1995 - El Paleolítico superior inicial en el País Vasco. Historia de las investigaciones, Férvedes, 2, Villalba, p. 9-22,.

ARRIZABALAGA A. et IRIARTE M. J. 2003 - El yacimiento arqueológico de Irikaitz (Zestoa, País Vasco). Descripción del depósito y caracterización industrial de

(14) La collection Genson est à présent conservée pour une partie au Musée Saint-Jacques de Béziers, pour l'autre au Musée archéologique de Narbonne. 
su nivel IV, in : XI Reunión Nacional de Cuaternario, AEQUA, Oviedo, p. 205-210,.

ARRIZABALAGA A., ALTUNA J., ARESO P., FALGUERES C., IRIARTE M.J., MARIEZKURRENA K., PEMÁN E., RUIZ ALONSO M., TARRIÑO A., URIZ A., VALLVERDÚ J. 2005 Retorno a Lezetxiki (Arrasate, País Vasco) : nuevas perspectivas de la investigación, In Santonja, Pérez-González \& Machado (dir.) - Geoarqueología y Conservación del Patrimonio. Actas de la IV Reunión de Geoarqueología, Madrid, p. 63-80.

BARANDIARÁN I. 1980 - Auriñaciense y Perigordiense en el País Vasco : Estado Actual, Munibe, 32, p. 325-333.

BARANDIARÁN I. 1988a - Actividad arqueológica en Navarra.1986-1987 : yacimiento de Mugarduia Sur (Urbasa). Campaña de 1987, Trabajos de Arqueología Navarra, 7, Gobierno de Navarra, Pamplona, p. 319-321.

BARANDIARÁN I. 1988b - Prehistoria : El Paleolítico, Historia General de Euskal Herria, Auñamendi, Donostia.

BARANDIARÁN I. 1996 - Le Paléolithique supérieur au Pays Basque et dans le Bassin de l'Ebre, In Le Paléolithique supérieur européen. Bilan quinquenal 19911996, UISPP, Forli, p. 319-322.

BARANDIARÁN I. 1997 - El paleolítico y el epipaleolítico. Arqueología de Vasconia Peninsular, Isturitz, 7, Eusko Ikaskuntza, p. 5-21.

BARANDIARÁN I., FORTEA J. et HOYOS M. 1996 - EI Auriñaciense tardío y los orígenes del Gravetiense: el caso de la región cantábrica, In XIII International Congress of UISPP. Colloquium XII, p. 263-293.

BARANDIARÁN J. M. 1934 - Euskalerri'ko Leen-gizona, Egia Sorta 1, Donostia, $108 \mathrm{p}$.

BARANDIARÁN J. M. 1950 - Bolinkoba y otros yacimientos prehistóricos de la Sierra de Amboto, Cuadernos de Historia Primitiva, 2, Madrid, p. 75-112.

BARANDIARÁN J. M. 1953 - El hombre prehistórico en el País Vasco, Ekin, Buenos Aires.

BARANDIARÁN J. M. 1974 - Una azagaya isturitzense en Bolinkoba (Abadiano, Vizcaya), Kobie, 5, p. 19-20.

BARANDIARÁN J. M. 1977 - Excavaciones en Jentilbaratza y Kobalde (Ataun) (Campaña de 1971), Munibe, 29, p. 195-212.

BARRIÈRE C. 1976 - L'art pariétal de la grotte de Gargas, Oxford, 2 vol., 409 p., 144 fig., 93 photos, (B.A.R. Supplementary Series, $n^{\circ} 14$ )

BARRIÈRE C. 1984 - La grotte de Gargas, In L'Art des Cavernes. Atlas des grottes ornées, Imprimerie Nationale, p. 514-522, 21 fig.
BÉGOUËN H. et BREUIL H. 1958 - Les cavernes du Volp. Trois-Frères, Tuc d'Audoubert, à Montesquieu-Avantès (Ariège). Paris, Arts et Métiers graphiques, 124 p., 115 fig., XXXII pl.

BÉGOUËN R. et CLOTTES J. - 1984 La grotte des TroisFrères, In L'art des Cavernes. Atlas des grottes ornées paléolithiques françaises, Ministère de la Culture, Imprimerie nationale, p. 400-409, 19 fig.

BOUCHUD J. 1958 - La faune de la grotte de Gargas, Bulletin de la Société méridionale de Spéléologie et de Préhistoire, t. V, 1954-55, p. 383-390 (extrait du Bulletin de la Société d'Histoire naturelle de Toulouse, 93)

BOUYSSONIE J. 1939 - La grotte de Tarté, In Mélanges de Préhistoire et d'Anthropologie offerts au Professeur Comte $H$. Bégouën, Toulouse, Édition du Muséum, Toulouse, p. 179-194, 9 fig.

BREUIL H. 1952 - Quatre cents siècles d'art pariétal. Les cavernes ornées de l'Age du Renne, Montignac, Centre d'Études et de Documentation préhistoriques, 413 p., 531 fig.

BREUIL H. 1953 - Gravures sur schiste périgordiennes de la caverne de Gargas, In : Mélanges Hamal Nandrin, Bulletin de la Société royale belge d'Anthropologie et de Préhistoire, 64, p. 42-50.

BREUIL H. et CHEYNIER A. 1958 - Les fouilles de Breuil et Cartailhac dans la grotte de Gargas en 1911 et 1913 , Bulletin de la Société méridionale de Spéléologie et de Préhistoire, t. V, 1954-55, p. 341-382 (extrait du Bulletin de la Société d'Histoire naturelle de Toulouse, 93).

BUI-THI-MAI et GIRARD M. 1984 - L'analyse pollinique de la grotte de Saint-de-Verges (Ariège), Bulletin de la Société préhistorique Ariège-Pyrénées, t. XXXIX, p.27-41, 4fig.

BUISSON D. 1990 - Les flûtes paléolithiques d'lsturitz (Pyrénées-Atlantiques), Bulletin de la Société préhistorique française, 87, 11-12, p. 420-433.

BUISSON D. 1996 - Brassempouy : présentation du site et problèmes posés par les fouilles récentes, In : DELPORTE $\mathrm{H}$. et CLOTTES J. (dir.), Pyrénées Préhistoriques - Arts et Sociétés, actes du 118e congrès national des sociétés historiques et scientifiques, Pau, 1993, Éditions du CTHS, p.423-437, 4 fig.

CASTAÑOS P. 1986 - Los Macromamíferos del Pleistoceno y Holoceno de Vizcaya. Faunas asociadas a los yacimientos arqueológicos, Tesis Doctoral inédita, Universidad del País Vasco, Leioa, 593 p.

CAZALS N., GONZALES URQUIJO J., TERRADAS $\mathrm{X}$. (coord.) 2007 - Fronteras naturales y fronteras culturales en los Pirineos prehistóricos. Actas del coloquio de Tarascon, 2004. Universidad de Cantabria. 
CHAUCHAT Cl. 1968 - Les industries préhistoriques de la région de Bayonne, du Périgordien ancien à l'Asturien, Thèse de $3^{\mathrm{e}}$ cycle de l'Université de Bordeaux I, 2 vol., 191 p., 60 pl.

CLOT A. 1973 - L'art graphique préhistorique des HautesPyrénées. Essai de synthèse et catalogue à l'occasion d'une exposition, Édition P.G.P, Morlaas, Imprimé à Zaragoza, 160 p., 168 fig., 8 pl. photos.

CLOTTES J. 1989 - Le Magdalénien des Pyrénées, in : Le Magdalénien en Europe - La structuration du Magdalénien, Actes du colloque de Mayence 1987, Xle Congrès de I'U.I.S.P.P., p. 281-360, 5 tabl., 32 fig. (ERAUL, $\mathrm{n}^{\circ} 38$ ).

CLOTTES J., VALLADAS H., CACHIER H. et ARNOLD M. 1992 - Des dates pour Niaux et Gargas, Bulletin de la Société préhistorique française, t. 89, n 9, p. 270-274.

COLLECTIF 2005 - Pyrénées-Magazine, 100, juillet-août, Milan Presse.

CORCHÓN RODRIGUEZ S. 1986 - El arte mueble paleolítico cantábrico : contexto y análisis interno, Ministerio de Cultura, Madrid, 482 p., 204 fig. (Monografías del Centro de Investigación y Museo de Altamira, 16).

DARTIGUEPEYROU S. 1995 - L'industrie lithique gravettienne du Chantier I à Brassempouy. Approche technologique, Mémoire de Maîtrise, Université Paris I - Panthéon Sorbonne, 99 p., 14 annexes, 17 tableaux.

DELPORTE H. 1968 - Brassempouy : ses industries d'après la collection Piette, Zephyrus, 1967, XVIII, p. 5-41, 7 fig.

DELPORTE H. 1979 - L'image de la Femme dans l'art préhistorique, Picard, Paris, $287 \mathrm{p}$.

DELPORTE H. 1995 - Brassempouy et la Dame de Brassempouy, In DELPORTE H. (éd.) - La Dame de Brassempouy, Actes du Colloque de Brassempouy, juillet 1994, Liège, p. 55-64 (ERAUL 74).

DELPORTE H. 1996 - Brassempouy : histoire d'un gisement, In : DELPORTE H. et CLOTTES J. (dir.), Pyrénées Préhistoriques - Arts et Sociétés, actes du 118e congrès national des sociétés historiques et scientifiques, Pau, 1993, Éditions du CTHS, p.415-421 2 fig.

DUPRÉ M. 1990 - Análisis polínico de la cueva de Amalda, In Altuna J., Baldeón A., Mariezkurrena K. (dir.) - La Cueva de Amalda (Zestoa, País Vasco). Ocupaciones paleolíticas y postpaleolíticas, Fundacion José Miguel de Barandiarán, San Sebastián, p. 49-51. (Colección Barandiarán : 4).

ESPARZA SAN JUAN X. 1995 - La cueva de Isturitz. Su yacimiento y sus relaciones con la cornisa cantábrica durante el Paleolítico superior, Madrid, Universidad Nacional de Educación a Distancia, 307 p., 92 fig., 12 tabl. (Aula Abierta, 82).
ESPARZA SAN JUAN X. et MÚJIKA ALUSTIZA J.A. 1996a - El Perigordiense superior en el Pais Vasco, In DELPORTE $\mathrm{H}$. et CLOTTES J. (dir.) - Pyrénées Préhistoriques. Arts et Sociétés, actes du $118 \mathrm{e}$ congrès national des sociétés historiques et scientifiques, Pau, 1993, Éditions du CTHS, p. 61-71, 1 fig.

ESPARZA SAN JUAN X. et MÚJIKA ALUSTIZA J.A. 1996b - La cueva de Isturitz en el Pirineo occidental, In DELPORTE H. et CLOTTES J. (dir.) - Pyrénées Préhistoriques. Arts et Sociétés, actes du 118e congrès national des sociétés historiques et scientifiques, Pau, 1993, Éditions du CTHS, p.73-86, 4 fig.

FOSSE Ph. 1992 - La grande faune d'Enlène EDG Remarques paléontologiques et archéozoologiques, Préhistoire ariégeoise, bulletin de la Société préhistorique Ariège-Pyrénées, t. XLVII, p. 195 - 220.

FOUCHER P. 2004 - Les industries lithiques du complexe Gravettien-Solutréen dans les Pyrénées. Techno-typologie et circulation des matières siliceuses de part et d'autre de l'axe Pyrénées-Cantabres, Thèse de l'Université de Toulouse-le-Mirail, 3 vol., 334 p., 253 fig., tabl. en Annexes.

FOUCHER P. 2006 - Gargas et l'Atlantique : les relations transpyrénéennes au cours du Gravettien. In : Homenaje al Prof. Jesús Altuna, Munibe, 57, 2005-2006, tome II : Arqueología, p. 131-147, 9 fig.

FOUCHER P. et SAN JUAN C. 1998 - Le complexe gravettien / solutréen des Pyrénées centrales : prospection thématique, Bilan scientifique 1997 du Service Régional de l'Archéologie de Midi-Pyrénées, Ministère de la Culture et de la Communication, p. 232.

FOUCHER P. et SAN JUAN C. 2004 - La grotte de Gargas (Aventignan, Hautes-Pyrénées) : rapport de fouille programmée 2004, Service régional de l'Archéologie de MidiPyrénées, 60 p., 19 fig.

FOUCHER P. et SAN JUAN C. 2005a - Le complexe gravettien / solutréen des Pyrénées centrales : prospection thématique, Bilan scientifique 2001 du Service Régional de l'Archéologie de Midi-Pyrénées, Ministère de la Culture et de la Communication, p. 171

FOUCHER P. et SAN JUAN C. $2005 \mathrm{~b}$ - La circulation des matières siliceuses dans le Gravettien pyrénéen, in : JAUBERT J. et BARBAZA M. (dir.) - Territoires, déplacements, mobilité, échanges durant la Préhistoire. Terres et Hommes du Sud, Actes du colloque CTHS de Toulouse, avril 2001, p. 199-217, 13 fig.

FOUCHER P., SAN JUAN-FOUCHER C. 2008 - Du silex, de l'os et des coquillages : matières et espaces géographiques dans le Gravettien pyrénéen, in AUBRY Th., ALMEIDA F., ARAÚJO A.-C., TIFFAGOM M. (dir.) - Space and Time: Which Diachronies, Which Synchronies, Which Scales ? / Typology vs. Technology. Actes du XV 
Congrès Mondial de l'Union Internationale des Sciences Préhistoriques et Protohistoriques (UISPP) de Lisbonne2006, vol. 21, Sections C64 et C65, p. 45-55, 2 fig., 1 tabl. (BAR International Series 1831).

FOUCHER P., SAN JUAN-FOUCHER C., FERRIER C., COUCHOUD I., VERCOUTÈRE C. 2008 - La grotte de Gargas (Aventignan, Hautes-Pyrénées) : nouvelles perspectives de recherche et premiers résultats sur les occupations gravettiennes, in : JAUBERT J., BORDES J.-G., ORTEGA I. Les sociétés paléolithiques d'un grand Sud-Ouest - Nouveaux gisements, nouvelles méthodes, nouveaux résultats. Actes des journées de la Société préhistorique française et de I'Université de Bordeaux I, nov. 2006, p. 301-324, 8 tabl., 13 fig. (Mémoire de la Société préhistorique française : 47).

FOUCHER P., SAN JUAN C. et MARTIN H. 2000 - Le site gravettien de La Carane-3 (Foix, Ariège), Bulletin de la Société préhistorique Ariège-Pyrénées, LIV, 1999, p. 15-42, 16 fig.

FOUCHER P., SAN JUAN-FOUCHER C. et RUMEAU Y. 2007 - La grotte de Gargas. Un siècle de recherches. Communauté de communes du canton de Saint-Laurentde-Neste, 126 p.

FOUCHER P., SAN JUAN C., VALLADAS H., CLOTTES J., BEGOUËN R. et GIRAUD J.-P. 2002 - De nouvelles dates ${ }^{14} \mathrm{C}$ pour le Gravettien des Pyrénées centrales, Bulletin de la Société préhistorique Ariège-Pyrénées, LVI, 2001, p. 35-44, 4 fig.

GAMBIER D., BON F. et GARDĖRE Ph. 2000 - - La grotte de Brassempouy (Pouy, Landes), Bilan scientifique 1999 du Service Régional de l'Archéologie de l'Aquitaine, Ministère de la Culture et de la Communication, p. 68-69.

GAMBIER D., BON F., GARDĖRE Ph. et MENSAN R. 2002 La grotte de Brassempouy (Pouy, Landes), Bilan scientifique 2001 du Service Régional de l'Archéologie de l'Aquitaine, Ministère de la Culture et de la Communication, p. 92.

GENSON E. 1934 - Contribution à l'histoire du plus vieux Languedoc méditerranéen. Le Solutréen dans le Languedoc méditerranéen. (Région Béziers-Narbonne), compte rendu de la dixième session du Congrès préhistorique de France, Nîmes-Avignon, 1931, Société Préhistorique Française, Paris, p. 117-119.

GOUTAS N. 2003 L'exploitation des bois de cervidés dans les niveaux gravettiens de la grotte d'Isturitz (PyrénéesAtlantiques) : le procédé d'extraction de baguette par double rainurage longitudinal In : PATOU-MATHIS, M. ; CATTELAIN, P. \& RAMSEYER, D. (coord.) L'industrie osseuse pré- et protohistorique en Europe. Approches technologiques et fonctionnelles, Actes du Colloque 1.6, XIVe congrès de I'UISPP, Liège, septembre 2001, Amay 2003, 19-28, 7 fig. (Bulletin du Cercle archéologique Hesbaye-Condroz 26, 2002).

GOUTAS N. 2004 - Caractérisation et évolution du Gravettien en France par l'approche techno-économique des industries en matières dures animales (étude de six gisements du Sudouest), Thèse de l'Université de Paris I, 2 vol. 675 p.

GROENEN M. 1987 - Les représentations des mains négatives dans les grottes de Gargas et de Tibiran (HautesPyrénées). Approche méthodologique, Mémoire présenté en vue de l'obtention du grade de Licencié en Histoire de l'Art et Archéologie, Université libre de Bruxelles, Faculté de Philosophie et Lettres, 2 vol. , 214 p., LX pl., 6 tab.

GROENEN M. 1988 - Les représentations de mains négatives dans les grottes de Gargas et de Tibiran (Hautes-Pyrénées) . Approche méthodologique, Bulletin de la Société royale belge d'Anthropologie et de Préhistoire, 99, p. 81-113.

HAHN J. 1999 - Flûtes aurignaciennes de la grotte de Geissen Klösterle, Jura Souabe, In Préhistoire d'os. Recueil d'études sur l'industrie osseuse préhistorique offert à $H$. Camps-Faber, Publications de l'Université de Provence, p. 159-163, 3 fig.

HÉLÉNA P. et T. 1930 - Rapport succinct des fouilles exécutées dans la grotte de la Crouzade (Aude) du 9 juillet au 6 août 1930, manuscrit, archives de l'Institut de Paléontologie Humaine, Paris, 8 p.

HÉLÉNA P. 1928 - La stratigraphie de la grotte de la Crouzade (commune de Gruissan, Aude), extrait du Bulletin de la Commission archéologique de Narbonne, tome XVII, (1926-1927), $50 \mathrm{p}$.

HÉLÉNA P. 1932 - Compte-rendu des travaux exécutés en 1932, dans la petite caverne de Bize, sous les auspices de I'Institut de Paléontologie humaine, manuscrit, archives de I'Institut de Paléontologie Humaine, Paris, 8 p.

HÉLÉNA P. 1934 - Nouvelles fouilles aux cavernes de Bize, In Compte rendu de la dixième session du Congrès préhistorique de France, Nîmes-Avignon, 1931, Société Préhistorique Française, Paris, p. 192-195.

HÉLÉNA T. 1924 - Le Paléolithique, rapport manuscrit, « envoyé au Dr Capitan le 5-1-1924 », archives de l'Institut de Paléontologie Humaine, Paris : 20 p. dont 3 fig.

JALUT G., AUBERT S., GALOP D., FONTUGNE M. et BELET J.M. 1996 - Type regions F-zg and F-r, the northern slope of the Pyrenees, In Berglung B.E., Birks H.J.B., Ralska-Jaziewiczowa - Palaeoecological events during the last 15000 years - Regional syntheses of Palaeoecological studies of lakes and mires in Europe, M., Wright H.E. (éd.), Wiley J. \& Sons, p. 612-632.

JALUT G., DELIBRIAS G., DAGNAC J., MARDONES M. et BOUHOURS M. 1982 - A palaeoecological approach to the last 21000 years in the Pyrenees : the peat bog of Freychinède (alt. $1350 \mathrm{~m}$, Ariège, South France), Palaeogeo., Palaeoclimatol., Palaeoecol., 40, p. 321-359.

KLARIC L. 2003 - L'unité technique des industries à burins du Raysse dans leur contexte diachronique. Réflexions sur 
la diversité culturelle au Gravettien à partir des données de la Picardie, d'Arcy-sur-Cure, de Brassempouy et du Cirque-de-la-Patrie. Thèse de l'Université de Paris I Panthéon-Sorbonne, 419 p., 144 fig.

LARRIBAU, J.D. et PRUDHOMME S. 1984 - La grotte d'Erberua, In L'art des Cavernes. Atlas des grottes ornées paléolithiques françaises, Ministère de la Culture, Imprimerie nationale, p. 275-279, 4 fig.

LEROI-GOURHAN A. 1967 - Les mains de Gargas. Essai pour une étude d'ensemble, Bulletin de la Société préhistorique française, 64, p. 107-122.

LIGNEREUX Y., VÉZIAN R. avec la coll. de PÉRIN N., MANHART H., à paraitre - La faune gravettienne de la Tuto de Camalhot (Saint-Jean-de-Verges, Ariège).

LUMLEY-WOODYEAR H. de 1972 - Le Paléolithique inférieur et moyen du Midi méditerranéen dans son cadre géologique, t. II, Bas-Languedoc - Roussillon - Catalogne, Paris, Éditions du CNRS, 443 p. ( $V^{\mathrm{e}}$ supplément à Gallia Préhistoire)..

MCCOLLOUGH M.-C. 1971 - Perigordian facies in the Upper Palaeolithic of Cantabria, Ph. D. Thesis, University of Pensilvannia, Michigan.

MERLET J.-C. 1996 - Le Périgordien supérieur et l'Azilien d'Arcet à Montaut (Landes), Archéologie des Pyrénées occidentales et des Landes, 15, p. 119-126.

MÉROC L. 1963 - L’Aurignacien et le Périgordien dans les Pyrénées françaises et dans leur avant-pays, In Aurignac et l'Aurignacien : centenaire des fouilles d'Édouard Lartet, p. 63-74, 3 fig. ( $n^{\circ}$ spécial du Bulletin de la Société méridionale de Spéléologie et de Préhistoire, t. VI-IX, 1956-1959).

MOVIUS H. L. Jr. 1973 - Quelques commentaires supplémentaires sur les sagaies d'Isturitz: données de l'abri Pataud, Les Eyzies (Dordogne), Bulletin de la Société préhistorique française, 70, 1, p. 85-89, 2 fig.

MUGICA J. A. 1983 - Industria de hueso en la Prehistoria de Guipúzcoa, Munibe, 35, p. 451-631, 17 ph., 2 fig.

MÚJIKA ALUSTIZA J.-A. 1991 - La industria ósea del Paleolítico superior y Epipaleolítco del Pirineo occidental, Tesis Doctoral inédita, Universidad de Deusto, Bilbao, 1351 p.

NORMAND Ch. 1993 - Un atelier de taille de pièces à dos à Tercis (Landes), Archéologie des Pyrénées occidentales et des Landes, 1992/1993, t. 12, p. 27-51, 6 fig.

NORMAND Ch. 1994 - Nouvelles données archéologiques sur Lezea (Commune de Sare, Pyrénées-Atlantiques), Archéologie des Pyrénées occidentales et des Landes, 13, p. 9-21, 3 fig.

NORMAND Ch. 2007 - Les Aurignaciens de la grotte d'Isturitz (communes d'Isturitz et de Saint-Martin-
d'Arberoue, Pyrénées-Atlantiques, France), In : FLOSS H., ROUQUEROL N. (dir.) - Les chemins de l'Art aurignacien en Europe. Das Aurignacien und die Anfänge der Kunst in Europa, Actes du colloque international d'Aurignac-2005, Éditions Musée-forum Aurignac, 89-104, 6 fig. 1 tabl.

NUIN J. 1994 - La ocupación prehistórica en el Valle de Etxauri (Navarra). Un estado de la cuestión y nuevas aportaciones, Cuadernos de Sección de PrehistoriaArqueología, 5, Eusko lkaskuntza, p. 113-140.

PASSEMARD E. 1944 - La caverne d'Isturitz en Pays Basque, Préhistoire, t. IX, p. 7-84, 63 fig., LXIV pl. h. t.

PRUDHOMME S. 1987 - L'art pariétal préhistorique des grottes d'Isturitz, d'Oxocelhaya et d'Erberua (Pays basque) : application de méthodes statistiques à l'art pariétal paléolithique du Pays basque. Thèse de doctorat du Muséum National d'Histoire Naturelle, 2 vol. 430 p.

RIPOLL S., BALDELLOU V., MUÑOZ F. y AYUSO P. 2005 - La Fuente del Trucho (Asque-Colungo, Huesca, Espagne), International Newsletter on Rock Art (INORA), 42, p. 8-11, 4 fig.

RUIZ IDARRAGA R. 1990 - El complejo Auriñaco-Perigordiense en el País Vasco, Munibe (Antropologia - Arkeologia), 42, p. 23-32.

SACCHI D. 1969 - Observations sur la stratigraphie de la Petite grotte de Bize (Aude), Atacina, 4, p. 3-25.

SACCHI D. 1973 - Les civilisations du Würmien récent dans le Narbonnais, In Narbonne archéologie et histoire, vol. I, Montlaurès et les origines de Narbonne, actes du XLV ${ }^{e}$ congrès de la Fédération Historique du Languedoc méditerranéen et du Roussillon, Montpellier 14-16 avril 1972, p. 9-18.

SACCHI D. 1981 - Les collections Héléna du Musée de Narbonne : Le Paléolithique supérieur et l'Epipaléolithique, Cahiers Ligures de Préhistoire et d'Archéologie, $n^{\circ}$ 25-26, (1976-1977), p.19-108.

SACCHI D. 1982 (avec la collaboration de Granier J., MAUREL M., VILETTE P.) - Catalogue de la collection Théodore Rousseau, fouilles de la Crouzade, Musée de Carcassonne, 1982, 60 p., 13 pl. h.-t.

SACCHI D. 1986 - Le Paléolithique supérieur du Languedoc occidental et du Roussillon, Paris, Éditions du CNRS, 284 p., 199 fig., XVI pl. h.t. (XXle supplément à Gallia Préhistoire).

SACCHI D. 1990 - Bases objectives de la chronologie de l'art mobilier paléolithique dans les Pyrénées septentrionales, In CLOTTES J. (dir.) - L'art des objets au Paléolithique, t. 1 : L'art mobilier et son contexte, Actes du colloque international de Foix-Le Mas d'Azil, novembre 1987, Paris (Actes des colloques de la Direction du Patrimoine, 8).

SÁENZ DE BURUAGA A. 1991 - El Paleolítico superior de la cueva de Gatzarria (Zuberoa, País Vasco), Vitoria-Gasteiz, Universidad del País Vasco, 426 p. (Anejos Veleia, 6). 
SÁENZ DE BURUAGA A. 1996 - La antigüedad prehistórica, in : Rivera A. (dir.).- Alava. Nuestra Historia, Ed. El Correo Español, Vitoria, p. 33-56.

SAHLY A. 1963 - Nouvelles découvertes dans la grotte de Gargas, Bulletin de la Société Préhistorique de l'Ariège, 18, p. $65-74,6$ fig.

SAHLY A. 1966 - Les mains mutilées dans l'art préhistorique, Thèse de doctorat ès Lettres (Toulouse), Tunis, 320 p., 128 fig.

SAINT-PÉRIER R. de 1922 - Statuette de femme stéatopyge découverte à Lespugue (Haute-Garonne), L'Anthropologie, 32, p. 361-381, 3 pl. h.t.

SAINT-PÉRIER R. de 1924 - Les fouilles de 1923 dans la grotte des Rideaux à Lespugue (Haute-Garonne), L'Anthropologie, 36, p. 15-40.

SAINT-PÉRIER R. de 1949 - Prototypes de harpons ou bases de sagaies, L'Anthropologie, 53, 1-2, p. 68-73, 1 fig.

SAINT-PÉRIER R. et S. de 1952 - La grotte d'Isturitz : les Solutréens, les Aurignaciens et les Moustériens, Paris, Masson, 264 p., 135 fig., XI pl. h.-t. (Archives de l'Institut de Paléontologie humaine : mémoire $n^{\circ} 25$ ).

SAN JUAN-FOUCHER C. 2004 - Le complexe Gravettien Solutréen dans les Pyrénées : cadre chrono-culturel et stratégie d'exploitation des ressources naturelles. Rapport de Projet collectif de Recherche, Service régional de l'Archéologie, Toulouse, 109 p.

SAN JUAN-FOUCHER C. 2006 - Industrie osseuse décorée du Gravettien des Pyrénées, In : Homenaje al Prof. Jesús Altuna, Munibe, 57, 2005-2006, tome III : Arte, Anthropologia y Patrimonio arqueológico, p. 95-111, 8 fig.

SAN JUAN-FOUCHER C. et FOUCHER P. à paraître - 90 ans après : relecture de l'art mobilier de la grotte de Gargas (Aventignan, Hautes-Pyrénées) à partir de pièces inédites provenant des fouilles Cartailhac-Breuil.

SAN JUAN-FOUCHER C. et FOUCHER P. à paraître Marine shell beads from the Gravettian at Gargas cave (Hautes-Pyrénées, France) : cultural and territorial markers, Actes du $2^{\text {nd }}$ Archaeomalacology Working Group MeetingICAZ, Santander, 19-22 February 2008,

SAN JUAN-FOUCHER C. et VERCOUTÈRE C. 2005 - Les "sagaies d'Isturitz" des niveaux gravettiens de Gargas (Hautes-Pyrénées) et de Pataud (Dordogne). Un exemple d'approche pluridisciplinaire et complémentaire de l'industrie osseuse, Préhistoire Anthropologie Méditerranéennes, 12, 2003, 75-94, 7 fig.

SÉRONIE-VIVIEN M. et M.-R., FOUCHER P. 2006 L'économie du silex au Paléolithique supérieur dans le Bassin d'Aquitaine. Le cas des silex à lépidorbitoïdes des Pyrénées centrales - Caractérisation et implications méthodologiques. Paléo, 18, p. 193-215, 10 fig.
SIMONET A. 2005 - Les armatures lithiques. Méthodes d'étude et enjeux : l'exemple des armatures gravettiennes d'Isturitz, DEA de l'université de Toulouse II-Le Mirail, $95 \mathrm{p}$.

SIMONNET R. 1999 - De la géologie à la Préhistoire : le silex des Prépyrénées. Résultats et réflexions sur les perspectives et les limites de l'étude des matières premières lithiques, Paléo, 11, p. 71-88, 14 fig., 4 tableaux.

TABORIN Y. 1993 - La parure en coquillage au Paléolithique, Paris, Éd. du CNRS, 538 p. (XXIXe supplément à Gallia Préhistoire).

TABORIN Y. 2001 - La parure des Gravettiens de l'Europe occidentale et centrale, Bulletin de la Société préhistorique Ariège-Pyrénées, LV, 2000, p. 11-18, 2 fig.

TARRIÑO A. 2001 - El sílex en la cuenca Vasco-Cantábrica y Pirineo Navarro : caracterización y su aprovechamiento en la Prehistoria. Tesis Doctoral Universidad del País Vasco, Leioa, $384 \mathrm{p}$.

TARRIÑO A. 2003 - La piedra como materia prima en la Prehistoria, in : Manos a la Piedra. Las herramientas de la Prehistoria, Bilbao, p. 17-30.

THIAULT M.H. 2001 - L'exploitation et la transformation de l'ivoire de Mammouth. Une étude technologique d'objets gravettiens de la grotte du Pape (Brassempouy, Landes), Gallia Préhistoire, 43, p. 153-174, 16 fig.

UTRILLA MIRANDA P. 2000 - El arte rupestre en Aragón, Caja de Ahorros, $94 \mathrm{p}$.

UTRILLA MIRANDA P. 2002 - El Paleolítico en el valle medio del Ebro : una "revista de prensa" en el cambio de milenio, Spal, Revista de Prehistoria y arqueologia, Universidad de Sevilla, 9, 2000, p. 81-108, 4 fig.

VERCOUTÈRE C. 2005 - Étude archéozoologique de la faune de la grotte de Gargas (collection des fouilles BreuilCartailhac 1911-1913), rapport dactylographié, 36p. 15 tabl., 10 fig.

VEZIAN J. 1989 - Les fouilles à l'entrée du Portel Ouest (Loubens, Ariège). Stratigraphie générale et passage du Paléolithique moyen au Paléolithique supérieur, Bulletin de la Société préhistorique de l'Ariège, t. XLIV, 225-2619 fig.

VEZIAN J. ET J. 1966 - Les gisements de la grotte de Saint-Jean-de-Verges (Ariège), Gallia Préhistoire, t. IX, fasc. 1, p. 93-130, 19 fig.

YRAVEDRA J. (sous presse) - Zooarqueología y Tafonomía en el yacimiento paleolítico de Amalda, in : Haws J. (cor.) Zooarchaeological Issues in Iberian Archaeology, IV Congreso de Arqueología Peninsular Faro. 14-19 Septiembre de 2004. 